NBER WORKING PAPER SERIES

\title{
A NEW DILEMMA: CAPITAL CONTROLS AND MONETARY POLICY IN SUDDEN STOP ECONOMIES
}

\author{
Michael B. Devereux
}

Eric R. Young

Changhua $\mathrm{Yu}$

Working Paper 21791

http://www.nber.org/papers/w21791

\author{
NATIONAL BUREAU OF ECONOMIC RESEARCH \\ 1050 Massachusetts Avenue \\ Cambridge, MA 02138 \\ December 2015
}

We thank seminar participants at the Hong Kong Institute for Monetary Research, the UBC macro-lunch, and the Board of Governors of the Federal Reserve Bank for comments. Devereux thanks SSHRC, and the Royal Bank of Canada for financial support as well as support from ESRC award ES/1024174/1. Young thanks the financial support and hospitality of the HKIMR and the Bankard Fund for Political Economy at the University of Virginia. Yu thanks the National Natural Science Foundation of China 71303044, and the financial support and hospitality of the HKIMR. All errors are our own. The views expressed herein are those of the authors and do not necessarily reflect the views of the National Bureau of Economic Research.

NBER working papers are circulated for discussion and comment purposes. They have not been peerreviewed or been subject to the review by the NBER Board of Directors that accompanies official NBER publications.

(C) 2015 by Michael B. Devereux, Eric R. Young, and Changhua Yu. All rights reserved. Short sections of text, not to exceed two paragraphs, may be quoted without explicit permission provided that full credit, including $\left({ }^{\circ}\right.$ notice, is given to the source. 
A New Dilemma: Capital Controls and Monetary Policy in Sudden Stop Economies

Michael B. Devereux, Eric R. Young, and Changhua Yu

NBER Working Paper No. 21791

December 2015

JEL No. E44,E58,F38,F41

\section{ABSTRACT}

The dangers of high capital flow volatility and sudden stops have led economists to promote the use of capital controls as an addition to monetary policy in emerging market economies. This paper studies the benefits of capital controls and monetary policy in an open economy with financial frictions, nominal rigidities, and sudden stops. We focus on a time-consistent policy equilibrium. We find that during a crisis, an optimal monetary policy should sharply diverge from price stability. Without commitment, policymakers will also tax capital inflows in a crisis. But this is not optimal from an ex-ante social welfare perspective. An outcome without capital inflow taxes, using optimal monetary policy alone to respond to crises, is superior in welfare terms, but not time-consistent. If policy commitment were in place, capital inflows would be subsidized during crises. We also show that an optimal policy will never involve macro-prudential capital inflow taxes as a precaution against the risk of future crises (whether or not commitment is available).

Michael B. Devereux

Department of Economics

University of British Columbia

997-1873 East Mall

Vancouver, BC V6T 1 Z1

CANADA

and NBER

mbdevereux@gmail.com

Eric R. Young

University of Virginia

ey2d@virginia.edu
Changhua Yu

China Center for Economic Research

National School of Development

Peking University

5 Yiheyuan Rd, Haidian,Beijing, 100871

China

changhuay@gmail.com 


\section{Introduction}

Recent experience of financial crises in many countries has altered the traditional support for fully open international capital markets. Many emerging market economies have opened up their financial markets in the last two decades and moved away from rigidly pegged exchange rates (see for instance LevyYeyati and Sturzenegger, 2005; Lane and Milesi-Ferretti, 2008). Despite this move toward openness, these countries have been subject to extremely volatile capital flows and crises associated with 'sudden stops' in capital inflows (Bacchetta and van Wincoop, 2000; Kaminsky et al., 2005; Reinhart and Reinhart, 2009; Fratzscher, 2012; Broner et al., 2013b). A new view has emerged suggesting that monetary policy alone cannot adequately manage the external shocks facing small emerging economies and must be supplanted with some type of capital control or macro-prudential policy (Farhi and Werning, 2012, 2014; Rey, 2015). The central logic behind this recent consensus is that the welfare case for fully open capital markets rests on a set of assumptions that fail to apply in contemporary international financial markets, so that capital controls may constitute a second best optimal policy response. This new 'orthodoxy' promotes the combination of capital controls and monetary policy as part of an optimal policy toolkit for open economies (The Economist, 2013).

Our paper revisits the case for capital controls in open economies with both financial frictions and nominal rigidities. We employ a simple model of a small open economy subject to occasional 'sudden stops'. Monetary policy and capital controls are potentially useful as macroeconomic instruments. We ask two simple questions: first, how useful is monetary policy in responding to financial crises associated with 'sudden stops' in capital flows, ; and second, what are the benefits of capital controls in addition to monetary policy?

The combination of sticky prices and financial constraints that depend on asset prices offer the possibility that monetary policy and capital controls may be used in tandem as part of an optimal policy. A substantial empirical and theoretical literature makes the case that financial frictions render conventional monetary policy tools less effective (see Cespedes et al., 2004; Devereux et al., 2006; Gertler et al., 2007; Braggion et al., 2009). ${ }^{1}$ At the same time, as we noted, a series of recent papers have noted the possibility that taxes on capital flows can correct pecuniary externalities associated with occasionally binding borrowing constraints (Bianchi, 2011; Benigno et al., 2013; Bianchi and Mendoza, 2010, 2013; Jeanne and

\footnotetext{
${ }^{1}$ Also see a recent survey by Frankel (2010).
} 
Korinek, 2010). In principle, we might expect that these two policy levers would support each other as part of an optimal policy package.

Before answering these questions, however, we place one further requirement on the policy design - we assume that policymakers lack commitment ability, so that both monetary and macro prudential policies have to be 'time-consistent' in the sense that previous policy promises will only be kept if they are in the interests of current decision makers (Klein et al., 2008). Subject to this requirement, we explore the combination of optimal monetary and capital controls policies in an environment with financial frictions and a combination of both internal and external shocks.

The central results of the paper are two-fold and quite striking. First, we find that there is a role for monetary policy to depart from the conventional optimal rule of maintaining strict price stability in face of 'sudden stop' crises which lead to binding borrowing constraints in the baseline model. In such states of the world, it is optimal for policy makers to provide some monetary stimulus and to allow a jump in domestic inflation. The degree to which monetary policy can usefully respond to sudden stops depends on how extensive are nominal rigidities - with sticky prices and wages, a highly active monetary policy is both effective and optimal. Second, we find that in a time-consistent optimal policy equilibrium, policy makers will find it optimal to impose capital inflow taxes in face of sudden stop crises. Such taxes will relax the external borrowing constraint and partly cushion the economy from the negative impact of the crises. But despite this positive effect, we find that capital controls are in fact welfare reducing. The time consistent equilibrium in which policy makers apply capital controls leads to excessively low asset prices and inefficiently low levels of net external debt accumulation by the small economy, relative to a policy outcome without capital controls.

In an environment where the policymaker lacks commitment, there is no guarantee that optimal policies maximize welfare, even if the policy-maker is purely benevolent. This observation is the same point that was first made by Kydland and Prescott (1977), but is implicit in a vast literature on dynamic public finance and macroeconomic models of monetary and fiscal policy. ${ }^{2}$ In our case, the key element underlying the problem of time-consistency is attributable to the nature of the borrowing constraints facing the small economy. As in Kiyotaki and Moore (1997) and Iacoviello (2005), we assume that the collateral constraint on borrowing is tied to the value of assets that obtains when the debt comes due. As a result,

\footnotetext{
${ }^{2}$ For instance see time-consistent monetary policy in Calvo (1978) and Barro and Gordon (1983); time-consistent fiscal policy in Benhabib and Rustichini (1997), Klein et al. (2008), Farhi et al. (2012) and others.
} 
a policymaker who is concerned with macro prudential tools must focus on easing borrowing constraints by targeting future asset prices. With full commitment in policy-making, this targeting would be done by promising to take actions in the future. But in the absence of commitment, the only tool available is to impose capital controls on current inflows in times of crises. In an equilibrium where all policymakers take these actions, capital controls are excessive and the economy undertakes too little borrowing.

The message of the paper is clear. Capital flow controls present an appealing additional policy lever for emerging market countries, particularly because they directly attack the sources of inefficiency in international capital markets. But without commitment in policy making, capital controls involve a severe problem of time inconsistency, leading to an outcome with excessive capital inflow taxes which is worse than an outcome with unregulated (and inefficient) capital flows. While the new orthodoxy suggests that in principle, capital controls may be a beneficial addition to policy, we argue that once we recognize the strategic setting in which policy is made, capital controls are not desirable.

How would the analysis differ if policy-makers had the ability to commit to an optimal policy? While we do not fully characterize the solution to the model under commitment, we show that an optimal policy with commitment should imply a subsidy to capital inflows during a crisis. But without commitment, as we have noted, capital inflows are taxed during a crisis.

Our analysis also has implications for the role of capital taxes as 'macro-prudential' policy. Should capital inflows be taxed during normal times in order to reduce the severity of crises when the crisis eventually hits? A number of recent papers have made the case for such macro prudential policy (see for instance Korinek, 2011, Bianchi and Mendoza, 2013). In our model, surprisingly, we find that macro prudential policy is never optimal, whether or not policy commitment is available.

This paper contributes to two growing branches of literature. First, it is related to the literature on the remedies for pecuniary externalities. During a financial crisis, the collateral constraint binds, which reduces the value of collateral, leading to an even tighter constraint, but private agents do not internalize this effect when issuing debt. This may lead to over borrowing in competitive equilibrium, relative to a social planner's outcome (Bianchi, 2011). ${ }^{3}$ Bianchi and Mendoza (2010) show that state-contingent capital inflow taxes will prevent overborrowing, which can be interpreted as a form of Pigouvian taxation (Jeanne and Korinek, 2010). When there exist ex post adjustments of production between tradable and nontradable

\footnotetext{
${ }^{3}$ The overborrowing result is relative to the allocation chosen by a constrained social planner or regulator that faces the same borrowing constraint; relative to an unconstrained or first-best allocation, the economy in Bianchi (2011) generates severe underborrowing.
} 
sectors, the economy could exhibit underborrowing relative to the constrained efficient outcome (Benigno et al., 2013). Korinek (2011) provides a comprehensive review on borrowing and macroprudential policies during financial crises. As for optimal capital controls, Bianchi and Mendoza (2013) and Benigno et al. (2012, 2014) explore time-consistent macroprudential policy. ${ }^{4}$

The most closely related paper to ours is Bianchi and Mendoza (2013). They also investigate the role of optimal, time consistent capital controls in a model with occasionally binding constraints. Our paper is distinguished from Bianchi and Mendoza (2013) in two dimensions. First of course we incorporate a useful role for monetary policy. Second but more importantly, in our model, the constraint on borrowing depends upon the expectation of the future (resale) value of assets, following the tradition of Kiyotaki and Moore (1997) and Iacoviello (2005), whereas Bianchi and Mendoza (2013) use the current value of assets. ${ }^{5}$ The different constraints lead to quite different incentives facing policymakers. Bianchi and Mendoza (2013), identify an important role for a macro prudential tax; a capital inflow tax that is levied in good times, when there is a positive probability of a binding constraint in the next period. Once a crisis occurs however, the capital inflow tax is set close to zero. Moreover, this time consistent policy will always raise welfare in their model. The reason is that a policymaker in their model needs to restrict capital inflows on the edge of a crisis in order to sustain current asset prices, the value of collateral and access to international capital market. By contrast we find that the policy maker will never use macro-prudential taxes - it is never optimal to tax capital flows outside of a crisis. But when there is a sudden stop, the policy maker imposes capital inflow controls to prop up the value of collateral assets in the future. But in an equilibrium, where capital inflow controls are always used in a crisis, the price of capital and external borrowing are pushed down so much that welfare is lower than that with unregulated capital markets.

Our paper is also related to recent studies exploring monetary policy in the context of financial crises. Rey (2015) and Passari and Rey (2015) present evidence that the global financial cycle constrains monetary policy even under the flexible exchange rate regime when capital flows are unrestricted, and recommend the use of capital flow management. Bruno and Shin $(2015 \mathrm{a}, \mathrm{b})$ provide a linkage between cross-border bank capital flows and global factors, particularly US monetary policy. Farhi and Werning (2012, 2014)

\footnotetext{
${ }^{4}$ Korinek and Simsek (2013) study an aggregate demand externality at the zero lower bound, wherein the inability of the nominal interest rate to drop below zero when needed to stimulate consumption creates a positive role for macroprudential policy. Since their paper is in a closed-economy setting the particular policies they advocate are quite different from ones that would arise in our model. In any case, our economy does not encounter the ZLB given a reasonable inflation target, so we can safely abstract from the issues they raise.

${ }^{5}$ Either constraint can be motivated by an underlying microeconomic model of lending with limited enforcement. It is an open question what type of constraint fits the data best.
} 
investigate optimal capital controls and monetary policy in a Gali and Monacelli (2005) type of small open economy model with risk premium shocks, and show that capital controls help restore monetary autonomy in a fixed exchange rate regime and work as terms of trade manipulation in a flexible exchange rate regime. ${ }^{6}$ The most related papers on exchange rate policy are Fornaro (2015) and Schmitt-Grohe and Uribe (2015). Fornaro (2015) considers a small open economy similar to ours but focuses on simple policy rules, whereas our paper investigates the optimal monetary policy and optimal capital controls. Schmitt-Grohe and Uribe (2015) study a model with fixed exchange rates, downward nominal wage rigidity, and free capital mobility. In their paper, a correctly scaled devaluation can eliminate the effects of wage rigidity. In contrast, our paper starts with a standard small open economy New Keynesian model with sticky prices and/or wages. The pecuniary externality arises from collateralized borrowing, which cannot be completely undone by monetary policy. This opens the possibility of exploring the combination of monetary policy and capital controls in our paper. The novel result of our paper is that while the case for the benefits of capital controls as a supplement to monetary policy is present in our model, the end result is that the use of capital controls leads to worse outcomes in equilibrium.

The rest of the paper is organized as follows. Section 2 presents the baseline model with sticky prices and characterizes the competitive equilibrium under a certain set of policy. Section 3 characterizes allocations under optimal monetary policy and optimal capital controls. Section 4 provides a simplified finite-period model and discusses the time-inconsistency problem in optimal capital controls. Section 5 calibrates the model and section 6 quantitatively conducts the positive and normative analysis of the baseline model. Section 7 extends the baseline model by allowing sticky prices and sticky wages. The last section concludes.

\section{The model}

We consider a monetary version of a small open economy akin to Mendoza (2010) and Cespedes, Chang and Velasco (2004). There exist infinitely lived firm-households with a unit measure in a small country. Competitive domestic firms import intermediate inputs and hire domestic labor and physical capital to produce wholesale goods. These wholesale goods are differentiated into various varieties by domestic monopolistically competitive final goods producers, which are then aggregated by competitive bundlers into consumption composites. These composites either are consumed by domestic households or exported

\footnotetext{
${ }^{6}$ Capital controls as terms of trade manipulation are first explored by Costinot et al. (2014) in a two-country deterministic endowment economy.
} 
to the rest of the world. International financial markets are incomplete. Domestic households can trade only foreign currency denominated, non-state contingent bonds with foreigners.

Wholesale good production takes a form of Cobb-Douglas production

$$
M_{t}=A_{t}\left(Y_{F, t}\right)^{\alpha_{F}} L_{t}^{\alpha_{L}} K_{t}^{\alpha_{K}}
$$

with $\alpha_{F}+\alpha_{L}+\alpha_{K} \leq 1$. $M_{t}$ denotes the production of wholesale good, $A_{t}$ is country-wide exogenous technological shock, $Y_{F, t}$ represents imported intermediate inputs, $L_{t}$ labor demand and $K_{t}$ physical capital.

Suppose that the price of intermediate inputs in the rest of world (denoted $P_{F, t}^{*}$ ) is exogenously given to the small economy. We posit that foreign demand for domestic consumption composites, $X_{t}$, is given by

$$
X_{t}=\left(\frac{P_{t}}{\mathcal{E}_{t} P_{t}^{*}}\right)^{-\rho} \zeta_{t}^{*}
$$

$\zeta_{t}^{*}$ stands for a foreign demand, $\mathcal{E}_{t}$ represents the nominal exchange rate, and $P_{t}^{*}$ is the foreign CPI price level, which we normalize to unity hereafter and so does $P_{F, t}^{*}=1 . \rho>1$ is the elasticity of substitution between imports and locally produced goods in the foreign consumption basket. ${ }^{7}$ The share of expenditures in the foreign country (the rest of world) on imports from the home country remains small enough to be ignored in the analysis.

\section{$2.1 \quad$ Firm-households}

A representative firm-household has preferences given by

$$
E_{0} \sum_{t=0}^{+\infty} \beta^{t} U\left(c_{t}, l_{t}\right)
$$

where $E_{0}$ stands for mathematical expectations conditional on information up to date $0 . R_{t+1}^{*}$ denotes the foreign real interest rate. We assume that the subjective discount factor is constrained by $\beta R_{t+1}^{*}<1$ to generate an equilibrium where firm-households are net borrowers in the deterministic steady state. The

\footnotetext{
${ }^{7}$ This foreign demand function can be derived from a world economy as of Gali and Monacelli (2005). $\rho$ characterizes the elasticity of substitution among varieties produced in the world.
} 
period utility function takes the GHH (Greenwood, Hercowitz and Huffman, 1988) form

$$
U\left(c_{t}, l_{t}\right)=\frac{\left(c_{t}-\chi_{\frac{l_{t}^{1+\nu}}{1+\nu}}^{1-\sigma}-1\right.}{1-\sigma}
$$

Similar to Mendoza (2010), households can borrow from abroad to finance consumption and imported intermediate inputs. Borrowing must be undertaken in foreign currency. ${ }^{8}$ Borrowing from abroad requires physical capital $k_{t+1}$ as collateral:

$$
\vartheta Y_{F, t} P_{F, t}^{*}\left(1+\tau_{N, t}\right)-B_{t+1}^{*} \leq \kappa_{t} E_{t}\left\{\frac{Q_{t+1} k_{t+1}}{\mathcal{E}_{t+1}}\right\}
$$

$B_{t+1}^{*}$ stands for domestic savings in dollar terms at the end of period $t$. The term $\tau_{N, t}$ captures the presence of a fiscal tax on intermediate imports, which is discussed below. Hence $Y_{F, t} P_{F, t}^{*}\left(1+\tau_{N, t}\right)$ represents the total expenditure on intermediate inputs in terms of the foreign good, and $\vartheta$ measures the fraction of imported inputs $Y_{F, t}$ which are financed in advance. $Q_{t+1}$ denotes the nominal capital price in domestic currency units, and $k_{t+1}$ is the capital that the household accumulates in period $t$. The parameter $\kappa_{t}$ characterizes the loan-to-value ratio in the spirit of Kiyotaki and Moore (1997). The interpretation of (5) is that the collateralized expected foreign currency value of the capital stock brought into the next period must be at least as great as the foreign currency value of household intertemporal borrowing plus the working capital loans that households take out within period $t$ to finance intermediate imports.

Firm-households are equal owners of domestic firms and consequently they make identical consumption and borrowing decisions. We write the decisions for the wholesale good producer explicitly. The determination of other factors and products can be obtained from the maximum of the representative firm's profits in the corresponding competitive factor and product markets, which are omitted in the firm-household's budget constraint. The representative firm-household faces the budget constraint

$$
P_{t} c_{t}+Q_{t} k_{t+1}+\frac{B_{t+1}}{R_{t+1}}+\frac{B_{t+1}^{*} \mathcal{E}_{t}}{R_{t+1}^{*}}\left(1-\tau_{c, t}\right) \leq W_{t} l_{t}+k_{t}\left(R_{K, t}+Q_{t}\right)+B_{t}+B_{t}^{*} \mathcal{E}_{t}+T_{t}
$$

\footnotetext{
${ }^{8}$ Empirical evidence shows that emerging economies borrow primarily in foreign currency from international investors (for instance see, Jeanne, 2003) and do so using short term bonds (see Broner, Lorenzoni and Schmukler, 2013a). In the literature this situation is called 'liability dollarization' and plays an important role in the financial accelerator that leads to sudden stops in our model. If bonds were denominated in local currency, during a sudden stop the value of outstanding debt would fall and mitigate the effects of the crisis.
} 


$$
+\left[P_{M, t} M\left(Y_{F, t}, L_{t}, K_{t}\right)-\left(1+\tau_{N, t}\right) Y_{F, t} P_{F, t}^{*} \mathcal{E}_{t}-W_{t} L_{t}-R_{K, t} K_{t}\right]+D_{t}
$$

The left-hand side of the equation displays consumption expenditures $P_{t} c_{t}$, purchases of capital $Q_{t} k_{t+1}$, bond purchases denominated in domestic currency $B_{t+1} / R_{t+1},\left(R_{t+1}\right.$ is the domestic nominal interest rate) and in dollars $B_{t+1}^{*} \mathcal{E}_{t} / R_{t+1}^{*}$. As in the literature (Bianchi and Mendoza, 2010; Farhi and Werning, 2012; Farhi and Werning, 2014), we assume that the government subsidizes foreign bond purchases at the rate of $\tau_{c, t}$. Hence $\tau_{c, t}>0$ is equivalent to a tax on foreign borrowing (if $\tau_{c, t}$ is negative this represents a subsidy to foreign borrowing). The right-hand side shows various income sources, including labor income $W_{t} l_{t}$, ( $W_{t}$ is the nominal wage) gross return on capital $k_{t}\left(R_{K, t}+Q_{t}\right),\left(R_{K, t}\right.$ is the marginal product of capital) gross return on domestic bond holdings $B_{t}$, foreign savings $B_{t}^{*} \mathcal{E}_{t}$, lump-sum transfers from government $T_{t}$, profits from wholesale good producers $P_{M, t} M_{t}-\left(1+\tau_{N, t}\right) Y_{F, t} \mathcal{E}_{t}-W_{t} L_{t}-R_{K, t} K_{t}$ and profits from other firms $D_{t}$. As noted above, we assume that wholesale producers are taxed by the fiscal authorities on their purchases of imported intermediate inputs at rate $\tau_{N, t}$. This tax is designed to exploit the country's implicit monopoly power in its export good, and is explicitly derived in the Appendix C. ${ }^{9}$ The wholesale good production $M_{t}$ is given by equation (1). We assume that working capital loans incur no interest rate payments as in Bianchi and Mendoza (2013).

Let $\mu_{t} e_{t}$ be the Lagrange multiplier associated with the collateral constraint (5). Let a lower case price variable denote the real price, i.e., $q_{t}=Q_{t} / P_{t}, w_{t}=W_{t} / P_{t}$. The consumer price index inflation rate is defined as $\pi_{t}=P_{t} / P_{t-1}$ and the real exchange rate (also the terms of trade) $e_{t}=\mathcal{E}_{t} P_{t}^{*} / P_{t}$. Higher $e_{t}$ implies depreciation of the real exchange rate. We can derive the first order conditions for household optimality as follows. The optimality condition for labor supply reads

$$
w_{t}=\chi l_{t}^{\nu}
$$

The optimality conditions for the household's portfolio choice over capital, domestic and foreign currency bonds yield

$$
\begin{gathered}
q_{t}=\mu_{t} \kappa_{t} E_{t}\left\{\frac{q_{t+1} e_{t}}{e_{t+1}}\right\}+E_{t}\left\{\beta \frac{U_{c}(t+1)}{U_{c}(t)}\left(r_{K, t+1}+q_{t+1}\right)\right\}, \\
1=E_{t}\left\{\beta \frac{U_{c}(t+1)}{U_{c}(t)} \frac{R_{t+1}}{\pi_{t+1}}\right\},
\end{gathered}
$$

\footnotetext{
${ }^{9}$ We see this assumption as essentially technical, designed to isolate the terms of trade externality from the pecuniary externality specific to the borrowing constraints. In the analysis below, $\tau_{N, t}$ will be set at a level so that in normal times, the policy authorities have no further incentive to manipulate the economy's terms of trade.
} 


$$
1-\tau_{c, t}=\mu_{t} R_{t+1}^{*}+E_{t}\left\{\beta \frac{U_{c}(t+1)}{U_{c}(t)} \frac{e_{t+1}}{e_{t}} R_{t+1}^{*}\right\}
$$

where $U_{c}(t)$ denotes the marginal utility of consumption. Condition (8) says that in choosing to acquire an additional unit of capital, the household trades off the cost of the capital against the expected benefit in terms of the returns and capital gains next period, adjusted by the stochastic discount factor, and in addition, there is a current benefit in terms of a looser borrowing constraint when $\mu_{t}>0$, which depends on the expected next period price of capital. Condition (10) indicates that the cost of purchasing a foreign currency bond $\left(1-\tau_{c, t}\right) / R_{t+1}^{*}$ must be weighed against the expected benefit next period in terms of the discounted return, plus the additional benefit which comes from a looser borrowing constraint when $\mu_{t}>0$.

The optimal demand for intermediate inputs, labor, and capital for the wholesale firm-household is given implicitly by

$$
\begin{gathered}
p_{M, t} \frac{\alpha_{F} M_{t}}{Y_{F, t}}=\left(1+\tau_{N, t}\right) e_{t}\left(1+\vartheta \mu_{t}\right), \\
p_{M, t} \frac{\alpha_{L} M_{t}}{L_{t}}=w_{t}, \\
p_{M, t} \frac{\alpha_{K} M_{t}}{K_{t}}=r_{K, t} .
\end{gathered}
$$

Note that (11) implies that the cost to the household-firm of importing intermediate inputs is increasing in the real exchange rate (which is also equivalent to the terms of trade in this setting) and also increasing in the multiplier on the collateral constraint $\mu_{t}$. Since intermediate inputs must be partially financed by borrowing, a tightening of the collateral constraint increases the real cost of importing for the firm. $w_{t}$ denotes the real cost of labor faced by a firm.

Finally, we can establish that the complementary slackness condition becomes

$$
e_{t} \mu_{t}\left[\kappa_{t} E_{t}\left(\frac{q_{t+1} k_{t+1}}{e_{t+1}}\right)+b_{t+1}^{*}-\vartheta\left(1+\tau_{N, t}\right) Y_{F, t}\right]=0
$$

where we have replaced the nominal bond $B_{t+1}^{*}$ with real bonds $b_{t+1}^{*}=B_{t+1}^{*} / P_{t}^{*}$.

\section{$2.2 \quad$ Final good producers}

There is a continuum of monopolistically competitive final good producers with measure one, each of which differentiates wholesale goods into a variety of final goods. Varieties are imperfect substitutes, and 
final good producers have a monopoly power over their varieties. All consumption varieties are aggregated into a consumption composite via a CES aggregator with elasticity of substitution $\theta$.

Let $P_{t}(i)$ be the price of variety $Y_{t}(i)$. Cost minimization implies that the price for the consumption composite can be written as

$$
P_{t}=\left(\int_{0}^{1}\left(P_{t}(i)\right)^{1-\theta} d i\right)^{\frac{1}{1-\theta}}
$$

and the demand for variety $Y_{t}(i)$ reads

$$
Y_{t}(i)=\left(\frac{P_{t}(i)}{P_{t}}\right)^{-\theta} Y_{t}
$$

The technology employed by a firm $i$ is linear

$$
Y_{t}(i)=M_{t}(i)
$$

Firms set prices in terms of domestic currency (whether for domestic sales or export). They can reset their prices each period but suffer an asymmetric price adjustment cost. Profits per period gained by firm $i$ equals total revenues net of wholesale prices and of price adjustment costs

$$
D_{H, t}(i) \equiv\left(1+\tau_{H}\right) P_{t}(i) Y_{t}(i)-P_{M, t} Y_{t}(i)-\phi\left(\frac{P_{t}(i)}{P_{t-1}(i)}\right) Y_{t} P_{t}
$$

with asymmetric price adjustment cost $\phi\left(\frac{P_{t}(i)}{P_{t-1}(i)}\right)$ following Varian (1975) and Kim and Ruge-Murcia (2009)

$$
\phi\left(\frac{P_{t}(i)}{P_{t-1}(i)}\right) \equiv \phi_{P} \frac{\exp \left(\gamma\left(\frac{P_{t}(i)}{P_{t-1}(i)}-\pi\right)\right)-\gamma\left(\frac{P_{t}(i)}{P_{t-1}(i)}-\pi\right)-1}{\gamma^{2}}
$$

where $\pi$ is the inflation target and $\tau_{H}$ denotes a subsidy rate by the government in order to undo the monopoly power of final good producers. In the price adjustment cost function $\phi(\cdot), \phi_{P}$ characterizes the Rotemberg price adjustment cost (see Rotemberg, 1982) and $\gamma$ captures the asymmetry of price adjustment cost. When $\gamma>0$, the price adjustment displays a pattern of upward rigidity, while $\gamma<0$ is for downward rigidity. ${ }^{10}$

\footnotetext{
${ }^{10}$ One can show that the second-order approximation to $\phi(\cdot)$ is $\frac{\phi_{P}}{2}\left(\frac{P_{t}(i)}{P_{t-1}(i)}-\pi\right)^{2}$, which is exactly the Rotemberg quadratic price adjustment cost. The asymmetry of price adjustment cost follows from the third-order component of $\phi(\cdot)$, $\frac{\phi_{P} \gamma}{6}\left(\frac{P_{t}(i)}{P_{t-1}(i)}-\pi\right)^{3}$.
} 
Firm $i$ solves

$$
\max _{\left\{P_{t}(i), Y_{t}(i)\right\}} E_{h}\left(\sum_{t=h}^{+\infty} \Lambda_{h, t} \frac{P_{h}}{P_{t}} D_{H, t}(i)\right),
$$

subject to demand for variety $i(15)$ and the production technology (16). The stochastic discount factor is given by $\Lambda_{h, t}=\beta^{t-h} U_{c}(t) / U_{c}(h)$ with $h \leq t$.

In a symmetric equilibrium, all firms choose the same price, $P_{t}(i)=P_{t}$, when resetting their prices. Consequently, the supply of each variety is identical: $Y_{t}(i)=Y_{t}$. The optimality condition for price-setting can be simplified as

$$
\begin{aligned}
& Y_{t}\left[\left(1+\tau_{H}\right)-\theta\left(1+\tau_{H}-p_{M, t}\right)\right]-\phi_{P} Y_{t} \pi_{t} \frac{\exp \left(\gamma\left(\pi_{t}-\pi\right)\right)-1}{\gamma}+ \\
& E_{t}\left[\Lambda_{t, t+1} \phi_{P} \pi_{t+1} Y_{t+1} \frac{\exp \left(\gamma\left(\pi_{t+1}-\pi\right)\right)-1}{\gamma}\right]=0 .
\end{aligned}
$$

Real profits from intermediate producers are

$$
\begin{aligned}
d_{H, t} & \equiv \frac{D_{H, t}}{P_{t}}=\left(1+\tau_{H}\right) Y_{t}-p_{M, t} Y_{t}-\phi\left(\pi_{t}\right) Y_{t} \\
& =Y_{t}\left[\left(1+\tau_{H}\right)-p_{M, t}-\phi\left(\pi_{t}\right)\right] .
\end{aligned}
$$

with

$$
\phi\left(\pi_{t}\right)=\phi_{P} \frac{\exp \left(\gamma\left(\pi_{t}-\pi\right)\right)-\gamma\left(\pi_{t}-\pi\right)-1}{\gamma^{2}}
$$

Notice that if there are no price adjustment costs, $\phi_{P}=0$, and no monopoly power for providing varieties, i.e. $\tau_{H}=1 /(\theta-1)>0$, we then have $p_{M, t}=1$.

\subsection{Market clearing conditions}

The labor market clearing condition implies that $l_{t}=L_{t}$. Per capita consumption must equal total consumption, so that $c_{t}=C_{t}$. If we assume that foreigners don't hold domestic currency denominated bonds, then the domestic bond market equilibrium requires $b_{t+1}=0$.

The capital stock is in fixed supply. The domestic capital market clearing condition yields $K_{t+1}=$ $k_{t+1}=1$. The wholesale good market clearing condition reads

$$
\int_{0}^{1} Y_{t}(i) d i=\int_{0}^{1} M_{t}(i) d i=M_{t}
$$


Consumption composites are either consumed by domestic households or exported to the rest of world

$$
Y_{t}\left[1-\phi\left(\pi_{t}\right)\right]=C_{t}+X_{t}
$$

Finally, profits from final good producers are $d_{t}=d_{H, t}$.

\subsection{Government policy}

To balance its budget, the government's lump-sum transfer is given by

$$
T_{t}=-\left(\tau_{H} Y_{t}+\tau_{N, t} Y_{F, t}+\frac{\tau_{c, t} b_{t+1}^{*} e_{t}}{R_{t+1}^{*}}\right) P_{t}
$$

The government chooses the production subsidy $\tau_{H}$, the tax on imports, $\tau_{N, t}$, and capital control $\tau_{c, t}$. We will look at various alternatives for monetary policy. In our baseline case, where monetary policy is not chosen optimally, we assume an inflation targeting rule represented by a Taylor rule:

$$
R_{t+1}=R\left(\frac{\pi_{t}}{\pi}\right)^{\alpha_{\pi}}\left(\frac{Y_{t}}{Y}\right)^{\alpha_{Y}}
$$

A variable without a superscript denotes the value of that variable at the deterministic steady state.

Combining firm-households' budget constraints (6) with the relevant market clearing conditions and taxation policy (21), we obtain that trade surpluses lead to net foreign asset accumulation:

$$
X_{t}-e_{t} Y_{F, t}=\left(\frac{b_{t+1}^{*}}{R_{t+1}^{*}}-b_{t}^{*}\right) e_{t}
$$

\subsection{Competitive equilibrium}

A competitive equilibrium consists of a sequence of allocations $\left\{L_{t}, C_{t}, Y_{F, t}, Y_{t}, K_{t+1}, b_{t+1}^{*}\right\}$, and a sequence of prices $\left\{w_{t}, q_{t}, \mu_{t}, R_{t+1}, r_{K, t}, e_{t}, \pi_{t}, p_{M, t}\right\}$, for $t=\cdots, 0,1,2, \cdots$, given fiscal subsidies $\tau_{H}$ and $\tau_{N, t}$, monetary policy $R_{t+1}$ and capital inflow policy $\tau_{c, t}$ chosen by the fiscal authority and monetary authority, such that (a) allocations solve households and firms' problem given the public policy and (b) prices clear corresponding markets. The full set of conditions for a competitive equilibrium is set out in Appendix A. 


\section{Optimal policy}

\subsection{Optimal monetary policy}

We first explore the environment where the policy-maker's options are restricted solely to monetary policy. The monetary authority solves a Ramsey planner's problem to maximize a representative household's lifetime utility. The optimal policy is implemented only by a monetary policy instrument; e.g. the nominal interest rate, within a regime of flexible exchange rates. Here we focus on the time-consistent optimal policy under discretion and look for a Markov-perfect equilibrium. ${ }^{11}$ The current planner takes as given the decisions of future planners but internalizes how those choices depend on the future debt level $b_{t+1}^{*}$ chosen today.

Assume that the constant subsidy rate $\tau_{H}$ is set at $\tau_{H}=1 /(\theta-1)$ to undo the monopoly power of differentiated producers in an economy without uncertainty. Likewise, we assume that the export tax is set at the rate $\tau_{N, t}=1 /(\rho-1)$ to offset the terms of trade monopoly. ${ }^{12}$ The monetary authority chooses the paths for inflation rates $\pi_{t}$ to maximize a representative household's life-time utility. Let the value function for a representative domestic firm-household be $V\left(b_{t}^{*}, Z_{t}\right)$ where $Z_{t}$ represents the set of exogenous state variables. The problem faced by the government reads,

$$
V\left(b_{t}^{*}, Z_{t}\right)=\max _{\{\Xi\}} U\left(\tilde{C}_{t}\right)+\beta E_{t} V\left(b_{t+1}^{*}, Z_{t+1}\right), \text { with } \tilde{C}_{t} \equiv C_{t}-\chi \frac{L_{t}^{1+\nu}}{1+\nu}
$$

with

$$
\Xi \equiv\left\{L_{t}, C_{t}, Y_{t}, Y_{F, t}, b_{t+1}^{*}, q_{t}, \mu_{t}, r_{K, t}, e_{t}, p_{M, t}, \pi_{t}\right\}
$$

subject to the set of competitive equilibrium conditions from Appendix A.

\subsection{Optimal monetary and capital control policies}

We now contrast the above problem with an expanded policy menu where the policy maker chooses both monetary policy and a policy for capital flow taxes. Again assume that the constant subsidy rate $\tau_{H}$ is set at $\tau_{H}=1 /(\theta-1)$ to undo the monopoly power in an economy without uncertainty and that an optimal export tax $\tau_{N, t}=1 /(\rho-1)$ is in place. Focus again on the time-consistent optimal Markov/Ramsey policy

\footnotetext{
${ }^{11}$ Non-Markovian equilibria are very difficult to compute. For a study of non-Markovian optimal policy in a closed-economy New Keynesian model, see Dong (2015).

${ }^{12}$ See Appendix $\mathrm{C}$ for an explicit derivation of these tax/subsidy rates.
} 
under discretion. But we now allow the optimal policy to be implemented both by a monetary policy instrument and a capital inflow tax $\tau_{c, t}$. The problem facing the planner with the option of capital taxes is equivalent to the optimal monetary policy problem except that the Euler equation for foreign bonds is omitted as a constraint. Then, given the solution to the extended planners problem, the optimal capital inflow tax $\tau_{c, t}$ can then be inferred from the condition

$$
\tau_{c, t}=1-\mu_{t} R_{t+1}^{*}-E_{t}\left\{\beta \frac{U_{c}(t+1)}{U_{c}(t)} \frac{e_{t+1}}{e_{t}} R_{t+1}^{*}\right\} .
$$

\section{A simplified example}

Before we present the solution to the full model, it is instructive to examine a simple finite-horizon example to build intuition for the results in the quantitative model. We assume a common world good, so there is no terms of trade movement, all prices are perfectly flexible, so there is no scope for monetary policy, and no monopolistic competition in domestic retail production, allowing us to ignore the distortion due to markup pricing. Our focus is solely on the comparison of capital inflow taxes/subsidies with and without commitment, when borrowing is restricted by collateral constraints.

There are only four time periods $t=0,1,2,3$. In period $t=0,1$, household borrowing has to be collateralized by domestic physical capital, whose values are endogenously determined by domestic markets. In period $t=2$, borrowing also is restricted by a collateral requirement but the value of collateral is exogenously given. In period $t=3$, no borrowing is undertaken, so there is no collateral constraint.

The advantage of allowing an exogenous credit limit in period $t=2$ is that the 'financial accelerator' operates only in the first two periods $t=0,1$. In the last period $t=3$, households repay all outstanding debt and consume all remaining income, so production, imports, labor supply and production are determined independently of credit conditions, and given production income, consumption only depends on the the level of debt inherited from period $t=2$. Physical capital depreciates completely after production in the last period. The structure of the model implies that decisions in the last two periods pin down the capital price in period $t=1$. Finally, the policy instrument available to a social planner is a capital inflow $\operatorname{tax} /$ subsidy $\tau_{c, t}$.

The model here is a finite period special case of the main model of section 2. The representative 
firm-household has utility defined by

$$
E_{0}\left\{\sum_{t=0}^{t=3} \beta^{t} U\left(c_{t}, l_{t}\right)\right\}
$$

The budget constraints for periods $t=0,1,2$ are given by

$$
q_{t} k_{t+1}+c_{t}+\frac{b_{t+1}^{*}}{R^{*}}\left(1-\tau_{c, t}\right)=q_{t} k_{t}+b_{t}^{*}+\left[A F\left(k_{t}, l_{t}, Y_{F, t}\right)-p_{F}^{*} Y_{F, t}\right]+T_{t}, t=0,1,2
$$

and budget constraint in the last period $t=3$ is

$$
c_{3}=b_{3}^{*}+\left[A F\left(k_{3}, l_{3}, Y_{F, 3}\right)-p_{F}^{*} Y_{F, 3}\right]
$$

The household faces a collateral constraint in the first two periods analogous to those described in the main model.

$$
\kappa_{t} E_{t}\left(q_{t+1} k_{t+1}\right) \geq-b_{t+1}^{*}+\vartheta p_{F}^{*} Y_{F, t}, t=0,1
$$

In period $t=2$, the collateral constraint is described by:

$$
\kappa_{t} \bar{q} \geq-b_{t+1}^{*}+\vartheta p_{F}^{*} Y_{F, t}, t=2
$$

where $\bar{q}$ is constant and defined in Appendix B. The initial debt condition $b_{0}^{*}$ is fixed.

The social planner chooses a capital flow tax/subsidy $\tau_{c, t}$ and returns the revenue accrued to the household with a lump-sum transfer. In period $t=2$, there is no benefit to a capital tax, so the planner will choose $\tau_{c, 2}=0$.

We compare outcomes where policymakers can commit to a sequence of capital flow taxes/subsidies at $t=0$ to one where policy is made with discretion recursively at times $t=1$ and $t=0$. It is also revealing to define a first-best outcome where borrowing may be undertaken without any financial frictions at all. The Appendix B describes the detailed conditions which define each policy outcome.

We assume that households have an incentive to front-load consumption; i.e. $\beta R^{*}<1$. In addition, assume perfect foresight, so all shocks are known at time $t=0$. In the first best equilibrium, production, income and employment are constant because of GHH preferences. Any pre-existing debt is paid down over time. Since $\beta R^{*}<1$, in the first-best equilibrium, household consumption decreases over time as well.

In the competitive equilibrium, with zero capital taxes, $\kappa_{t}$ and initial debt are set so that the borrowing 
constraint binds for period $t=0,1,2 .{ }^{13}$

Figure 1 illustrates the solution to the finite period model in the competitive equilibrium with zero capital taxes, compared to the first best outcome. The economy begins with initial assets $b_{0}^{*}=-0.2$, and debt must be zero at the end of period $t=3$, so in all cases, debt must be drawn down before the end period. In the first best case, labor supply, imported intermediates and output are constant across periods, and effective consumption has a slight downward sloping profile. Debt is reduced evenly across periods and is zero at the end of period $t=3$. The price of capital starts high and falls smoothly over time, since capital is worth nothing in the last period.

In a competitive equilibrium, households cannot issue new debt in the amount required to sustain the first-best consumption path. As a result, the collateral constraints become binding, effective consumption is constrained, and labor supply and output are below the first-best level. The binding collateral constraint reduces the household's equilibrium discount factor, and pushes down the profile of asset prices, leading to a further tightening of the debt constraints through the debt-deflation process. Figure 1 shows that in the competitive equilibrium with binding constraints, the consumption profile is sharply upward sloping, the Lagrange multiplier on the collateral constraint is positive and falling over time, leading to an inefficiently low level of labor supply, imported intermediates, and output. Since the collateral constraint is gradually relaxed, output and both inputs rise over time until at $t=3$ they attain their first-best level. The asset price falls below that of the first-best in all periods. ${ }^{14}$

With commitment, the planner in period $t=0$ can choose a sequence of consumption, borrowing, employment and imported inputs to maximize household utility for $t=0,1,2,3$, constrained by the collateral constraints, the firm-households profit maximization conditions, and the pricing equation for the capital stock. This last equation can be represented as follows for periods $t=0,1$ and $t=2$, respectively:

$$
q_{t}=E_{t}\left\{\beta \frac{U_{c}(t+1)}{U_{c}(t)}\left(r_{K, t+1}+q_{t+1}\right)\right\}+\mu_{t} \kappa_{t} E_{t}\left\{q_{t+1}\right\}, t=0,1
$$

\footnotetext{
${ }^{13}$ We set the leverage parameter to $\kappa_{t}=0.4$ for $t=0,1,2$ and initial assets $b_{0}^{*}=-0.2$. Structural parameter values are the same as those in the infinite-period model (see table 3 ) except that $\alpha_{F}=0.16$ and $\vartheta=0.5$, which will be described in detail later. The parameter governing the share of working capital is set to $\vartheta=0.5$, which is much lower than that in the infinite-period model. The reason is that the capital price in the four-period model is much lower than that in the full dynamic model. The import share is set to $\alpha_{F}=0.16$, and $\alpha_{K}=1-\alpha_{F}-\alpha_{L}$, to make the graphs more visible. Alternative parameterizations do not change the qualitative results.

${ }^{14}$ Katagiri, Kato and Tsuruga (2013) show that in this model the optimal policy is to intervene to set the multiplier equal to zero in any period in which it would otherwise be positive; that policy is time-consistent and implements the first-best allocation. The size of the required interventions may be prohibitive for real economies where other constraints on policymakers may become relevant; the size of the required transfers gets larger as the economy approaches the natural debt limit.
} 
(a) Beginning-of-period Bond

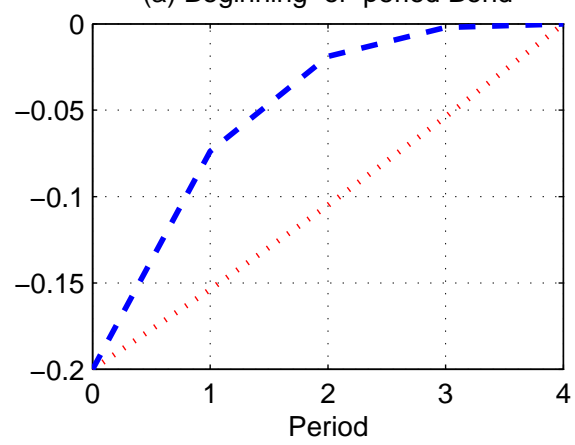

(c) Lagrange multiplier

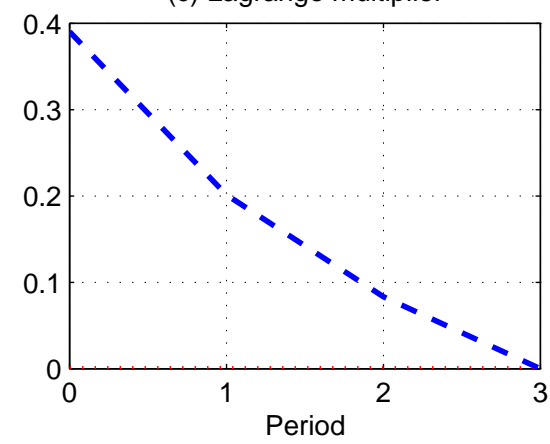

(e) Import

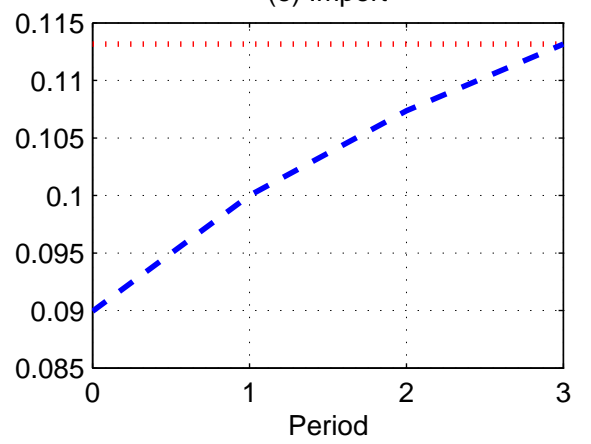

(b) Effective consumption

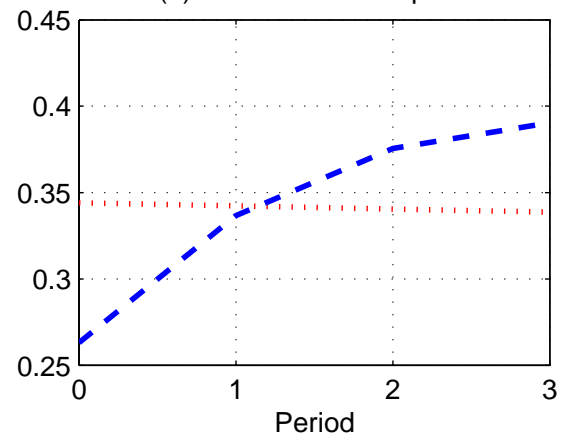

(d) Capital price

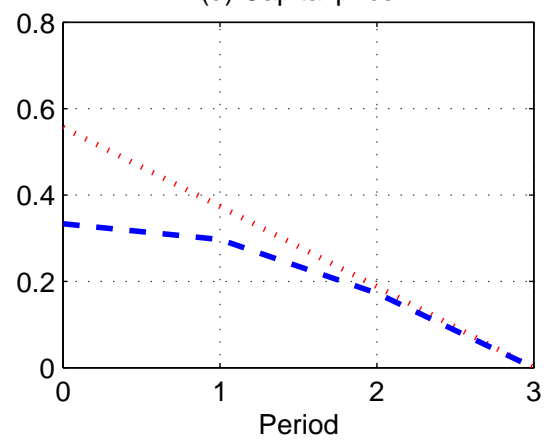

(f) Labor

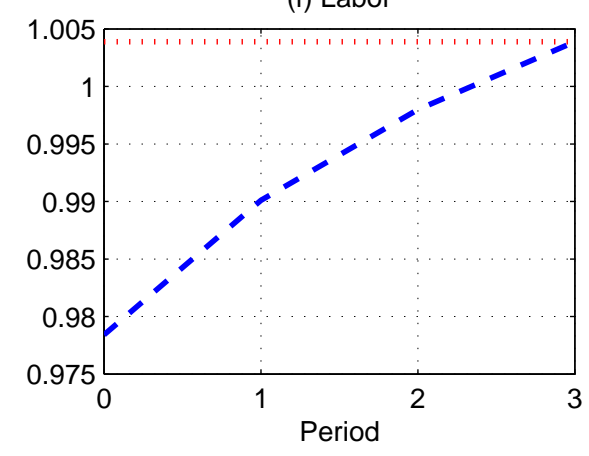

First best - - - Competitive equilibrium

Figure 1: A four-period model. Variables in the first best allocation and in the competitive equilibrium without capital controls. 
(a) Beginning-of-period Bond

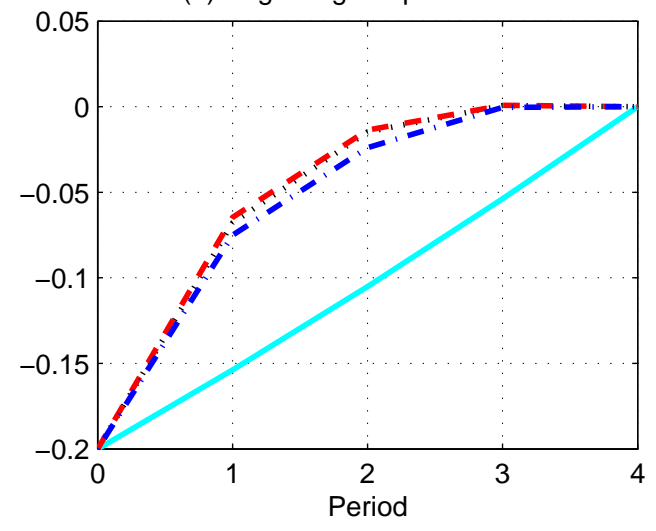

(c) Lagrange multiplier

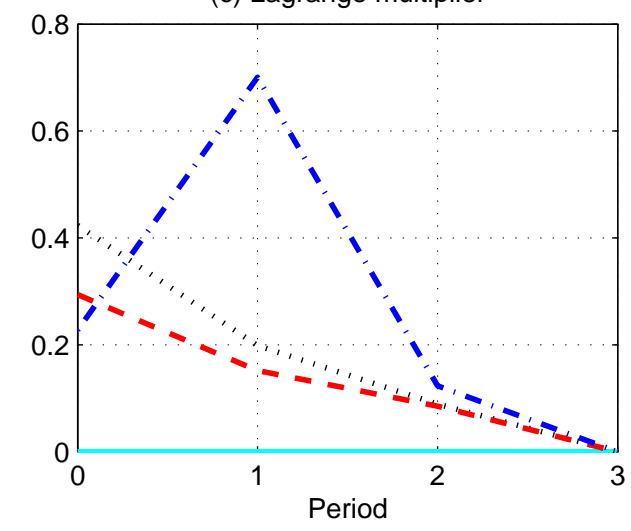

(b) Effective consumption

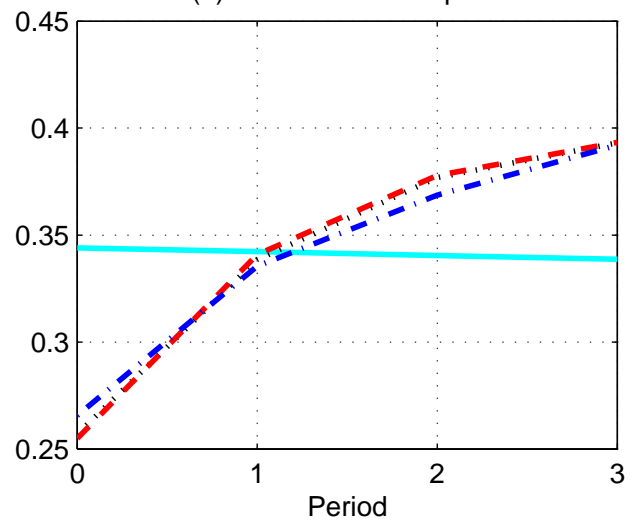

(d) Capital price

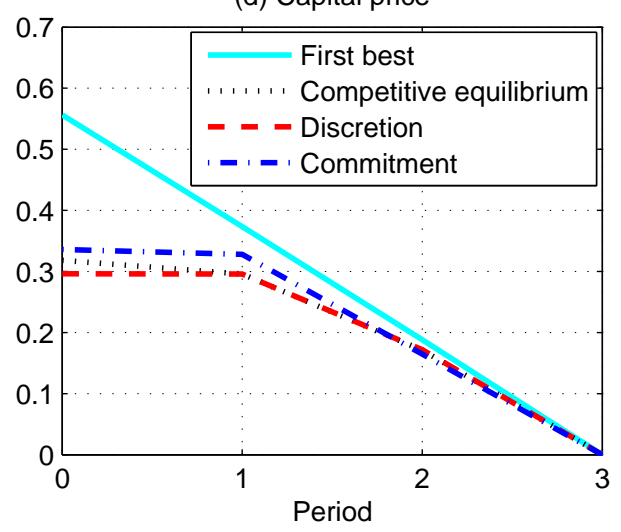

Figure 2: A four-period model. Variables in the competitive equilibrium without capital controls, optimal capital controls with full commitment and optimal capital controls with discretion. 


$$
q_{2}=E_{2}\left\{\beta \frac{U_{c}(3)}{U_{c}(2)}\left(r_{K, 3}+q_{3}\right)\right\}
$$

The planner attempts to relax the collateral constraint so as to flatten the time profile of effective consumption, relative to that of the competitive equilibrium. To achieve this goal, the planner needs to raise $q_{1}$, since this is the asset price governing the first period collateral constraint. This can be done by raising the equilibrium discount factor for $t=1$, through a capital inflow subsidy applied in period $t=1$. The easing of the collateral constraint leads to a fall in the Lagrange multiplier for $t=0$, which encourages increased period $t=0$ consumption, relative to period $t=1$ consumption. Since the optimal policy requires maintaining high period $t=1$ consumption relative to $t=2$ consumption, the planner balances the capital inflow subsidy in period $t=1$ with an inflow tax in period $t=0$ (see the upper panel of table 1).

Figure 2 describes the full response of the economy in the commitment outcome. The pattern is nonmonotonic. Since an optimal policy to ease collateral involves subsidizing period $t=1$ consumption, the collateral constraint binds more tightly at $t=1$ relative to the competitive equilibrium, while it is relaxed in period $t=0$ (relative to the competitive equilibrium). As a result, output and inputs rise relative to the initial competitive equilibrium in the first period, but fall in the second period. But the policy is successful at moving the consumption profile more in the direction of the first best outcome and leads to a uniformly higher price of capital.

Under discretion, the planner sets the capital control conditional on the state in each period (here the level of borrowing and exogenous shocks). Unlike the case with commitment, the planner ignores the impact of current policy on past planner decisions. Given debt levels at period $t=1$, the planner will choose allocations to maximize the representative agent's welfare from $t=1$ onwards. Then, taking the policy functions implied by the planner's decisions at $t=1$ as given, the planner in $t=0$ will choose an optimal allocation for $t=0$.

Figure 2 describes the time path of the relevant variables under the discretionary policy as described above. Again, the planner would like to maximize welfare of the representative agent by tilting the effective consumption profile more to the present, relative to that in the competitive equilibrium. But without commitment, the time $t=1$ capital flow policy cannot be credibly determined by the planner at time $t=0$. Rather, the time $t=1$ policy is chosen by the planner at time $t=1$, taking the time $t=1$ level of external debt and the currently binding collateral constraint as given. From the perspective of 
Table 1: Optimal capital inflow tax and welfare in the simplified model

Panel A: Optimal capital inflow tax (\%)

Commitment Discretion

$\begin{array}{lll}\text { Period } t=0 & 14.8 & 14.8\end{array}$

Period $t=1 \quad-53.0 \quad 4.1$

Panel B: Welfare change relative to competitive equilibrium (\%)

First Best Commitment Discretion

$3.25 \quad 0.32 \quad-0.03$

Notes: Welfare is measured by the certainty equivalence of effective consumption.

Table 2: Optimal capital inflow tax and welfare in a model with alternative credit constraints

\begin{tabular}{|c|c|c|}
\hline \multicolumn{3}{|c|}{ Panel A: Optimal capital inflow tax (\%) } \\
\hline & Commitment & Discretion \\
\hline Period $t=0$ & 0.5 & 0.5 \\
\hline Period $t=1$ & -11.1 & -11.2 \\
\hline \multicolumn{3}{|c|}{ Panel B: Welfare change relative to competitive equilibrium (\%) } \\
\hline First Best & Commitment & Discretion \\
\hline 0.78 & 0.06 & 0.06 \\
\hline
\end{tabular}

time $t=1$, the planner wishes to relax the $t=1$ constraint. Any policy which targets the $q_{1}$ price will not directly affect the time $t=1$ collateral constraint. Rather, the planner at time $t=1$ attempts to increase the asset price $q_{2}$ by imposing a capital inflow tax, reducing the level of debt brought into period $t=2$. By increasing the equilibrium discount factor, for any initial level of debt $-b_{1}^{*}$ that the time $t=1$ planner is faced with, she can raise $q_{2}$ by reducing the debt level brought into period 2. So, instead of subsidizing capital inflows in period 1, as the full commitment policy would do, the time consistent planner taxes inflows at time 1 .

The time $t=0$ policy can then be computed from the perspective of the planner at time 0 , taking as given the actions of the time $t=1$ planner. Again, the optimal policy for the $t=0$ planner is to attempt to raise $q_{1}$. But she cannot do raise $q_{1}$ now by committing to a capital subsidy in time $t=1$, since she doesn't have this commitment ability. The optimal time consistent policy is to impose an even slightly higher capital inflow tax in time $t=0$ than that under commitment, which again by raising the equilibrium discount factor, increases the the asset price $q_{1}$. 
When we put together the time path of capital taxes in the time consistent policy profile, we see, remarkably, that the optimal policy under discretion leads to an effective consumption profile which is in fact steeper than that of the untaxed competitive equilibrium, with a profile of borrowing for $t=0$ and $t=1$ that is lower than the competitive equilibrium. The optimal policy under discretion exacerbates the degree to which the collateral constraints restrict the household's borrowing profile. Another way to see this result is to note that the asset price at time $t=1$, which determines the initial borrowing level, and the time profile of consumption, is lower than that under commitment and also (marginally) lower than that in a competitive equilibrium.

Hence, a lack of commitment can lead to a capital control policy outcome that is not just ineffective, but is perverse, resulting in a time profile of consumption, asset prices and debt that is further away from the efficient level than would be a constrained competitive equilibrium without any policy at all. The bottom panel of table 1 establishes this result in terms of welfare: relative to the competitive equilibrium, welfare is higher under commitment and lower under discretion.

It is instructive to compare these results to those that would apply if collateral were valued at the current price $q_{t}$ (as in Bianchi and Mendoza, 2013, for instance), rather than the expected price tomorrow $E_{t}\left[q_{t+1}\right] \cdot{ }^{15}$. Table 2 presents the results for optimal capital taxes with this alternative collateral constraint. Capital controls and welfare under discretion are almost the same as those under commitment in this case. Under discretion, the policymaker at period $t=1$ wants to relax the credit constraint by increasing the asset price in that period, $q_{1}$. Subsidizing capital inflows can increase consumption in that period, which in turn leads to a higher current asset price. This capital inflow subsidy is essentially equivalent to that which would be chosen in period $t=0$ under commitment. ${ }^{16}$

\section{The Quantitative Model}

\subsection{Calibration}

The model period is one quarter. Table 3 lists parameter values in the baseline model. The preference parameters are quite standard and taken from the literature. In normal times without a binding constraint,

\footnotetext{
${ }^{15}$ The fact that $k_{t}$ rather than $k_{t+1}$ serves as collateral in Bianchi and Mendoza (2013) does not make a significant difference, since the only difference is whether a particular term is multiplied by $\beta$.

${ }^{16}$ Note that Bianchi and Mendoza (2013) primarily focus on macroprudential policy, which requires capital flow taxes applied in periods before financial distress occurs. We discuss the relevance of macroprudential taxes in our model below.
} 
optimal inflation equals its target. Therefore, domestic nominal interest rates reflect domestic real interest rates. We set the subjective discount factor $\beta=0.975$, in line with the literature for emerging economies (Uribe and Yue, 2006; Aguiar and Gopinath, 2007), implying an annual real interest rate of 10\%. Relative risk aversion is set to $\sigma=2$ and the inverse of Frisch labor supply elasticity is $\nu=1$.

The leverage shock $\kappa_{t}$ determines the borrowing capacity in a country. We take a two-state Markov chain to capture the leverage shock: $\kappa_{L}=0.35$ and $\kappa_{H}=0.5$. These two states are consistent with the leverage change from pre-crisis period to crisis period for US nonfinancial corporations (Graham, Leary and Roberts, 2014) and the corporate leverages in Asian emerging economies (IMF, 2014). ${ }^{17}$ The transition matrix is given by

$$
\Pi_{l}=\left[\begin{array}{cc}
p_{L, L} & 1-p_{L, L} \\
1-p_{H, H} & p_{H, H}
\end{array}\right] .
$$

We set $p_{L, L}=0.775$ and $p_{H, H}=0.975$ such that the duration of a high leverage regime equals 40 quarters and the unconditional probability of a low leverage regime is 10\% (Bianchi and Mendoza, 2013), implying that a typical leverage crisis will happen every ten years.

Parameters in the production function are set to match imports share (15\% of GDP, see Hanson, 2012), labor share (65\% of GDP, see Mendoza, 2010) and the external debt-GDP ratio (40\%) in emerging economies before the Global Financial Crisis. ${ }^{18}$ Given the leverage specification above and relevant ratios, we set $\alpha_{F}=0.13, \alpha_{L}=0.57$ and $\alpha_{K}=0.03$. Parameter $\vartheta$ is set to 1.3 , implying a share of working capital 20\% of GDP (Mendoza, 2010). ${ }^{19}$ The equilibrium labor supply in normal times (without credit constraints) is normalized to be one, which implies that $\chi=0.4$.

Nominal rigidity is introduced through a Rotemberg price adjustment cost. Price adjustment takes around four quarters. We set $\phi_{P}=76$ as in Aruoba, Cuba-Borda and Schorfheide (2013), and assume a small downward price rigidity $\gamma=-100 .^{20}$ Following the new Keynesian literature (Christiano, Eichenbaum and Evans, 2005; Gali, 2015), we set the elasticity of varieties in both domestic and foreign con-

\footnotetext{
${ }^{17}$ Mendoza (2010) uses a similar leverage $\kappa_{t}=0.2$ and $\kappa_{t}=0.3$ in his analysis.

${ }^{18}$ Data from World Development Indicators show that, just before the onset of the Global Financial Crisis, many emerging economies accumulated a large amount of external debt stocks, around $40 \%$ of Gross National Income. Data source: World Development Indicators with indicator code: DT.DOD.DECT.GN.ZS.

${ }^{19}$ Note that $\vartheta$ captures the role of working capital only when credit constraints bind. This value is higher than Mendoza (2010) and Bianchi and Mendoza (2013), but is consistent with Uribe and Yue (2006).

${ }^{20}$ The Rotemberg price adjustment cost relates the Calvo price stickiness via $\phi_{P}=\alpha(\theta-1) /((1-\alpha)(1-\alpha \beta))$ in an economy without collateral constraints (Khan, 2005). $1-\alpha$ measures the probability of Calvo style price adjustment in each period. Empricial evidence shows that prices rise faster than fall (Peltzman, 2000) and small price increases occur more frequently than small price decreases for price changes (Chen, Levy, Ray and Bergen, 2008).
} 
Table 3: Parameter values

\begin{tabular}{|c|c|c|}
\hline Parameter & & Values \\
\hline \multicolumn{3}{|l|}{ Preference } \\
\hline$\beta$ & Subjective discount factor & 0.975 \\
\hline$\sigma$ & Relative risk aversion & 2 \\
\hline$\nu$ & Inverse of Frisch labor supply elasticity & 1 \\
\hline$\chi$ & Parameter in labor supply & 0.4 \\
\hline \multicolumn{3}{|l|}{ Production } \\
\hline$\alpha_{F}$ & Intermediate input share in production & 0.13 \\
\hline$\alpha_{L}$ & Labor share in production & 0.57 \\
\hline$\alpha_{K}$ & Capital share in production & 0.03 \\
\hline$\vartheta$ & Share of working capital & 1.3 \\
\hline$\phi_{P}$ & Price adjustment cost & 76 \\
\hline$\gamma$ & Asymmetry of price adjustment cost & -100 \\
\hline$\theta$ & Elasticity of substitution among imported varieties & 10 \\
\hline$\rho$ & Elasticity of substitution in the foreign countries & 10 \\
\hline$\zeta$ & Steady state of foreign demand shock & 0.101 \\
\hline$R^{*}$ & Steady state of world interest rate & 1.015 \\
\hline$A$ & Steady state of TFP shock & 1 \\
\hline$\rho_{A}$ & Persistence of TFP shocks & 0.95 \\
\hline$\sigma_{A}$ & Standard deviation of TFP shocks & 0.008 \\
\hline$\rho_{R}$ & Persistence of foreign interest rate shocks & 0.6 \\
\hline$\sigma_{R}$ & Standard deviation of foreign interest rate shocks & 0.00623 \\
\hline$p_{H, H}$ & Transitional probability of high leverage to high leverage & 0.975 \\
\hline$p_{L, L}$ & Transitional probability of low leverage to low leverage & 0.775 \\
\hline \multicolumn{3}{|c|}{ Policy variables } \\
\hline$\alpha_{\pi}, \alpha_{Y}, \alpha_{e}$ & Coefficients in the Taylor rule & \\
\hline$\tau_{H}$ & Subsidy to final goods producers & $\frac{1}{\theta-1}$ \\
\hline$\tau_{N, t}$ & Gross subsidy to exports & $\frac{0-1}{\rho-1}$ \\
\hline
\end{tabular}


sumption baskets as $\theta=\rho=10$, implying a price markup of $11 \%$.

The real exchange rate is normalized to be one in a deterministic steady state when the collateral constraint binds, which requires $\zeta_{t}^{*}=0.101$. Domestic productivity and the foreign interest rate each follow an $\mathrm{AR}(1)$ process:

$$
\begin{aligned}
& \ln \left(A_{t+1}\right)=\left(1-\rho_{A}\right) \ln (A)+\rho_{A} \ln \left(A_{t}\right)+\epsilon_{A, t+1} \\
& \ln \left(R_{t+1}^{*}\right)=\left(1-\rho_{R}\right) \ln \left(R^{*}\right)+\rho_{R} \ln \left(R_{t}^{*}\right)+\epsilon_{R, t+1}
\end{aligned}
$$

where mean productivity is normalized to be one $A=1$ and the world quarterly real interest rate $R^{*}=1.015$ (Mendoza, 2010). We assume that the local productivity shock is uncorrelated with the global liquidity shock. ${ }^{21}$ Following the literature (i.e., Backus, Kehoe and Kydland, 1992), we set the standard deviation of the productivity shock to $\sigma_{A}=0.008$ and its persistence to $\rho_{A}=0.95$. The standard deviation of the foreign interest rate is set to $\sigma_{R}=0.00623$ and its persisence $\rho_{R}=0.60$ (Rudebusch, 2002, 2006). We then discretize the continuous AR(1) process into a two-state Markov chain based on Tauchen and Hussey (1991) in the computation of the model. ${ }^{22}$

\subsection{Solution method}

We solve the model using time iteration, as in Coleman (1990) and Benigno et al. (2013). When necessary, we use a homotopy algorithm to solve the system of nonlinear equations (Eaves and Schmedders, 1999; Devereux and Yu, 2014). To solve the Ramsey problems we follow Benigno et al. (2012, 2014) and solve the nonlinear optimization problem using feasible sequential quadratic programming. ${ }^{23}$ All functions are approximated using B-splines. The Appendix G provides details about the algorithms solving the model.

\footnotetext{
${ }^{21}$ Allowing for correlated shocks would slightly change households' precautionary savings but would not alter the main messages in this paper.

${ }^{22}$ Adding additional states into the Markov chain alters the quantitative answers but not the qualitative ones.

${ }^{23}$ specifically, we use the NLPQLP routine developed by Schittkowski (2014), who we thank for providing the code.
} 


\section{Results}

\subsection{Competitive equilibrium with strict inflation targeting}

We first assume a simple policy rule whereby the central bank sets inflation equal to the target: i.e. a price stability rule. This rule is equivalent to the Taylor rule described above with a very high weight on inflation deviations from target. ${ }^{24}$ In order to put the policy comparisons on an equal basis, we also assume that in the competitive equilibrium with strict inflation targeting, the fiscal authority imposes the constant taxes described above to correct the distortions due to monopoly power and the terms-of-trade manipulation. ${ }^{25}$

The model exhibits the characteristics of Fisherian debt-deflation described in previous literature. A leverage shock that causes the collateral constraint to bind leads to a spike in $\mu_{t}$, forcing debt to fall, leading also to a fall in import demand, output, and current and expected future asset prices. This in turn exacerbates the shock by further tightening the collateral constraint.

These responses to a leverage shock are described in the Figure 3, which illustrates the policy mapping from initial debt levels to the endogenous variables of the model, conditional on different shock outcomes. The Figure illustrates the effect of a shift from the best shock to the worst shock, given the existing level of assets $b_{t}^{*}{ }^{26}$ The panels of the Figure show the outcomes for current asset prices, the real exchange rate, the Lagrange multiplier and borrowing. We see that both $q_{t}$ and $E_{t}\left(q_{t+1} / e_{t+1}\right)$ declines sharply when $b_{t}^{*}$ is in the region where the constraint binds. In each panel we see that the collateral constraint is substantially more likely to bind, for given $b_{t}^{*}$, for the worst shock states. As the collateral constraint becomes binding, there is a kink in the policy function. For instance, given the realization of $\kappa_{t}$ a fall in $b_{t}^{*}$ which precipitates a binding constraint causes the mapping $b_{t+1}^{*}\left(b_{t}^{*}\right)$ to become flatter, as the collateral constraint reduces the borrowing capacity of the economy. By contrast, the mapping from $b_{t}^{*}$ to production and output becomes steeper, as the binding collateral constraint increases the effective cost of imports.

What role does the real exchange rate play in the dynamics? From Figure 3, we see that as debt

\footnotetext{
${ }^{24}$ While not optimal as defined by the time-consistent Ramsey problem, this rule is useful as a comparison since it represents an optimal monetary policy in a wide variety of modern new Keynesian settings both in closed and open economies (e.g. Gali, 2015)

${ }^{25}$ Thus, we are not considering the incentive to use monetary policy to substitute for these taxes, as is done by Costinot, Lorenzoni and Werning (2014). It seems clear that such a substitution is welfare-reducing, since the nominal interest rate is being put to a task it is not suited ideally to perform; instead, it is optimal to give the government an additional tool.

${ }^{26}$ The 'best shock' refers to scenarios when domestic households face low foreign interest rate, high domestic productivity and high domestic leverage, while the 'worst shock' is the case with high foreign interest rate, low domestic productivity and low domestic leverage.
} 

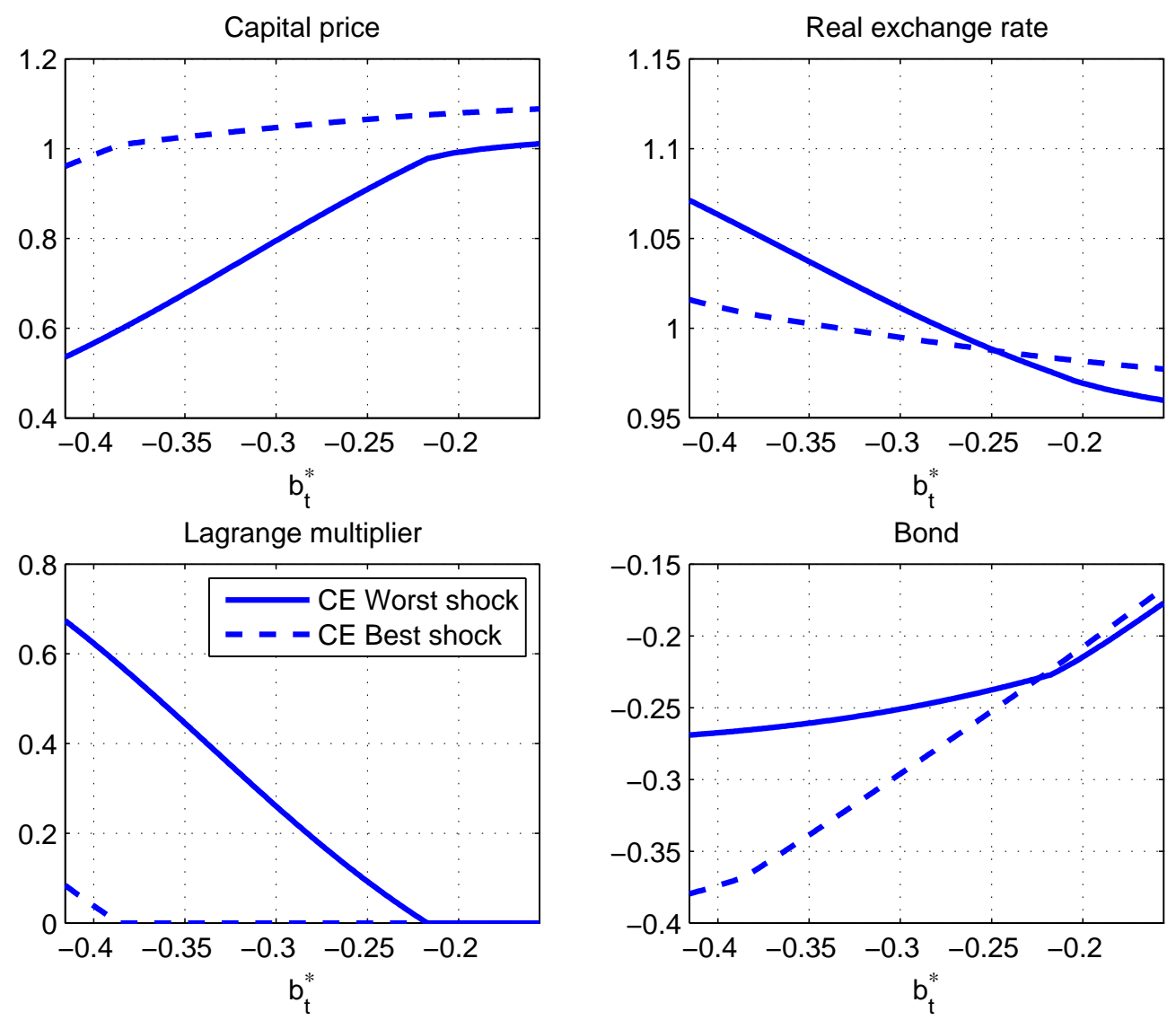

Figure 3: Policy functions in the competitive equilibrium with strict inflation targeting. The 'best shock' refers to policy functions when domestic households face low foreign interest rate, high domestic productivity and high domestic leverage, while the 'worst shock' shows the case with high foreign interest rate, low domestic productivity and low domestic leverage. 

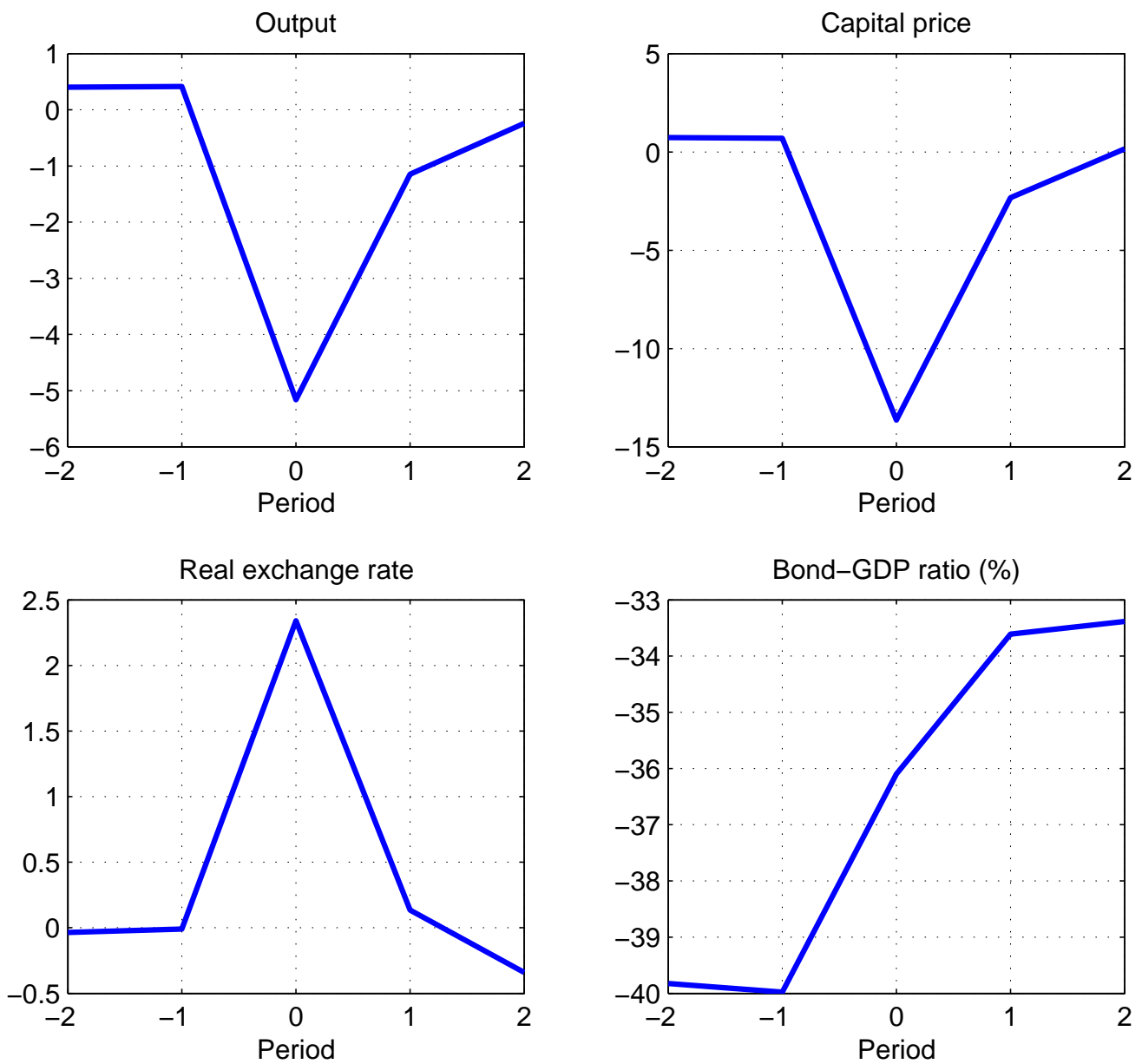

Figure 4: Event analysis in the competitive equilibrium with strict inflation targeting. A typical five-period event window is chosen as: (a) no binding collateral constraints in the first two periods $t=-2,-1$, (b) binding constraint at period $t=0$ and (c) no restrictions in the last two periods $t=1,2$. The events in the figure are an average of all event series in a simulation of 200,000 periods. Each panel reports the percent deviation from the unconditional mean of that variable except for the Bond-GDP ratio. 
increases, for a given exogenous state, the economy experiences continued real exchange rate depreciation. Intuitively, given higher initial debt levels, the path of consumption must be lower and lower, and in order to replace this fall in demand for domestic goods, the real exchange rate must depreciate. This is associated with a gradual fall in intermediate imports, employment and output. As debt rises above the threshold where the collateral constraint binds, there is a sharper fall in consumption, and a much steeper relationship between debt and the real exchange rate. The real exchange rate depreciation leads to a larger fall in imported intermediates, exacerbating the negative impact of the binding borrowing constraint.

But the real exchange rate plays an additional role with respect to the borrowing constraint. As we noted above, the one period ahead expected value $E_{t}\left(q_{t+1} / e_{t+1}\right)$ begins to decline sharply as external debt approaches the point where the collateral constraint is likely to bind. An expectation that the collateral constraint will bind in the immediate future must also imply an anticipated sharp future real exchange rate depreciation (as explained below), which leads to a tightening of the present collateral constraint.

We can see the dynamics of a crisis in Figure 4, which presents a consecutive five-period window of 'event analysis', where the event is defined in the following way: collateral constraints don't bind in the first two periods $t=-2,-1$, only bind at period $t=0$ and there are no restrictions on collateral constraints in the last two periods $t=1,2$. As the constraint binds in period 0 there is a sharp rise of the Lagrange multiplier $\mu_{0}$, which precipitates a persistent decline in foreign debt and a steep fall in imported intermediates, labor, output, and consumption. The price of capital also falls sharply, and as noted, there is a substantial real exchange rate depreciation.

\subsection{Optimal monetary policy}

The analysis so far assumed that monetary policy follows a strict inflation targeting rule, whether the economy is in crisis or not (whether the collateral constraint is binding or not). We now explore the time consistent Ramsey optimal monetary policy in the model with occasionally binding collateral constraints. As described in sub-section 3.1 above, for now, we focus attention solely on the use of a monetary policy instrument (e.g. the nominal interest rate), assuming no possibility for a capital flow tax.

Figures 5 describe the equilibrium policy functions for the time consistent Ramsey equilibrium (we also include the competitive equilibrium with strict inflation targeting for contrast). Again the Figure describes the equilibrium mapping from net foreign assets to the endogenous variables, conditional on different values for the leverage shocks, but now rather than representing the competitive equilibrium, this represents the 
mapping implied by the optimal monetary rule. When the collateral constraint is not binding (in the Figure this requires that $b_{t}^{*} \geq-0.217(-0.385)$ for the worst (best) shock) the optimal monetary rule is identical to the strict inflation targeting competitive equilibrium. The inflation rate is maintained strictly equal to the target rate independent of the realization of the leverage shock. ${ }^{27}$

As debt rises above the these thresholds however, so that the collateral constraint is binding, we see that monetary policy does diverge from the strict inflation targeting rule. Figure 5 shows that in the case of the worst (best) shock realization, as $b_{t}^{*}$ falls below $-0.217(-0.385)$ the policy maker raises the inflation rate above zero, and inflation rises monotonically with the level of external debt. Given the aggregate Philips curve implied by the price setting equation (17), the rise in inflation provides a stimulus offsetting the negative aggregate demand effects of the leverage shock. As Figure 5 shows, intermediate imports, employment, and total output fall by less under the optimal monetary policy than under the strict inflation targeting policy.

In the event analysis, which is not reported here, we compare the events under an optimal monetary policy and under the strict inflation targeting policy. The main difference between the two is that output, employment and intermediate imports fall by less under an optimal monetary policy. But since the crisis is not persistent, this difference has a negligible effect of the response of domestic consumption relative to the inflation targeting policy. Likewise, the real exchange rate and the price of capital respond almost identically under an optimal monetary policy as under the inflation targeting rule. We conclude from this result and from the fact that outside the crisis period optimal monetary policy adheres to strict inflation targeting that, under this specification for price nominal rigidities, while optimal monetary policy should depart from inflation targeting during a crisis, it does so simply to provide an aggregate demand stimulus. Monetary policy plays no clear macro-prudential role, neither by attempting to tighten so as to reduce debt accumulation before the crisis, nor to ease the degree to which the borrowing constraint is binding during the crisis (to see this last point note that the Lagrange multiplier response under strict inflation targeting is essentially equivalent to the response under an optimal monetary policy during the crisis).

\footnotetext{
${ }^{27}$ This statement is not trivial. Although the leverage constraint does not bind when $b_{t}^{*}$ satisfies the conditions stated in the previous sentence, the shocks are persistent, and it could be the case that a severe leverage shock combined with a debt level close to the threshold would precipitate a response of monetary policy designed to reduce the risk future binding constraints.
} 

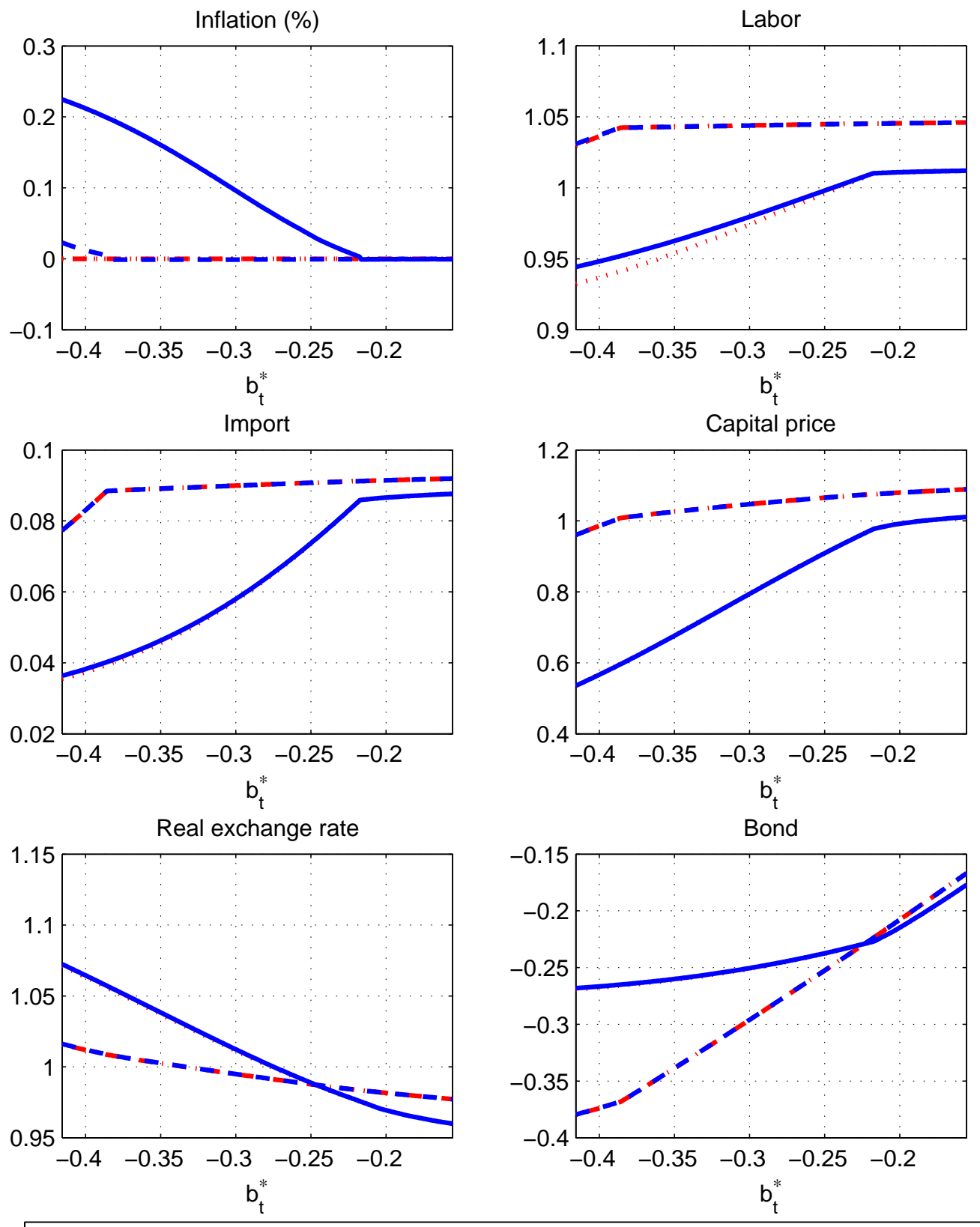

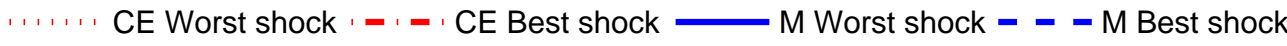

Figure 5: Policy functions in the optimal monetary policy without capital controls $(\mathrm{M})$ and the competitive equilibrium with strict inflation targeting $(\mathrm{CE})$. The 'best shock' refers to policy functions when domestic households face low foreign interest rate, high domestic productivity and high domestic leverage, while the 'worst shock' shows the case with high foreign interest rate, low domestic productivity and low domestic leverage. 


\subsection{Optimal monetary and capital controls}

We now combine monetary policy with capital controls, where the policy-maker may employ capital inflow controls with monetary policy responses. Before analyzing the full solution to the time-consistent Ramsey problem with capital controls, we ask what incentive would the planner have to employ capital inflow controls, in addition to utilizing optimal monetary policy as described above. To understand these incentives, we display one of the first order conditions from the Ramsey problem without nominal rigidities as follows (see Appendix D):

$$
1=\beta E_{t} \frac{U_{c}(t+1)}{U_{c}(t)} \frac{e_{t+1}}{e_{t}} R_{t+1}^{*}+\mu_{t} R_{t+1}^{*}+\tau_{c, t}
$$

with

$$
\tau_{c, t} \equiv \frac{\mu_{t} R_{t+1}^{*}}{\rho}\left[-1+(\rho-1) \kappa_{t} E_{t} \frac{\partial\left(q_{t+1} / e_{t+1}\right)}{\partial b_{t+1}^{*}}\right]
$$

The first condition may be interpreted as follows. The left hand side measures the cost of increasing saving this period (accumulating net foreign assets) in terms of the foreign good. The right hand side measures the benefits which are three-fold. First, there is the increase in net wealth brought into the next period, which increases utility through an increase in consumption. Second, there is the benefit to private households in terms of relaxing the current collateral constraint, measured by the second expression on the right hand side. The third expression, denoted $\tau_{c, t}$, decomposed in the second equation, captures the net additional benefit to foreign assets perceived by the planner, and thus represents the incentive for the planner to intervene directly in capital flows. We see this comprises of two parts, one negative, and one positive. Thus, in principle, the planner may wish to set a negative or positive tax on capital inflows, or equivalently, to subsidize or tax foreign borrowing. Moreover, the relative strength of the two components depends on the foreign elasticity of demand for home exports $\rho$. With a very low elasticity, it is more likely

that $\tau_{c, t}<0$, so that foreign borrowing is subsidized. But as $\rho$ rises, given that $E_{t}\left(\partial\left(q_{t+1} / e_{t+1}\right) / \partial b_{t+1}^{*}\right)>0$, it is more likely that $\tau_{c, t}>0$.

To understand the logic behind these two components, take the first component. This arises due to the presence of the constant import tax $1+\tau_{N}$ designed to offset the terms of trade externality. With a constant import tax, private households face a different marginal benefit of an additional unit of borrowing than does the planner. When the collateral constraint binds, private households perceive an additional 
unit of debt has an excess cost $\mu_{t} / e_{t}$ in terms of domestic consumption. But the planner facing the same calculation takes into account that an additional unit of debt will increase consumption by $e_{t}\left(1+\tau_{N}\right)$, which is the marginal product of intermediate imports in production. So the planner's excess cost of debt is evaluated as $\mu_{t} /\left(e_{t}\left(1+\tau_{N}\right)\right)$, which is less than that of the private sector. For this reason alone, the planner would wish to subsidize borrowing. The lower is $\rho$, the elasticity of foreign demand for domestic exports, the higher is $\tau_{N}$, and the higher is the motivation to subsidize foreign borrowing.

Against this, however, is the fact that when the collateral constraint binds, the planner will wish to take actions to relax the constraint. She can do this by increasing net foreign assets brought into the next period, thereby increasing period $t+1^{\prime} s$ capital price, since $\partial\left(\frac{q_{t+1}}{e_{t+1}}\right) / \partial b_{t+1}^{*}>0$. This effect depends on the planner explicitly taking account of the equilibrium mapping from net foreign assets to future asset prices, which is implicit in the time-consistent policy choice. These choices in turn relax the collateral constraint in the current period. Since this margin is not taken into account by private households, the desire to raise period $t+1$ capital price through this channel leads the planner to impose a capital inflow tax when the period $t$ collateral constraint binds.

In the calibrated model below, we find that the second factor is always dominant, so that the time consistent planner will always impose a capital inflow tax, when $\mu_{t}>0 .^{28}$

We now summarize the outcome under optimal capital controls under discretion in the following proposition.

Proposition 1. When $\rho$ is large enough, $\tau_{c, t}>0$ if $\mu_{t}>0$ under discretion.

Note that the planner ignores the impact of a capital tax on the current asset price $q_{t}$, since this has no direct bearing on the planner's problem. ${ }^{29}$. We can formally show that the planner will never impose a tax at time $t$ unless the constraint is currently binding, even under commitment; that is, capital controls are never prudential in the sense of Jeanne and Korinek (2013).

Proposition 2. If $\mu_{t}=0$, then $\tau_{c, t}=0$.

Proof. See Appendix E.

\footnotetext{
${ }^{28}$ With nominal rigidities, the expression for $\tau_{c, t}$ becomes more complicated; nevertheless, the quantitative results show that optimal inflation is essentially equal to its target and price stickiness doesn't matter for optimal capital controls. Therefore, $\tau_{c, t}$ defined in the main text can capture the driving forces in the baseline model with nominal rigidities. When both wages and prices are sticky, as in section 7 , the issue becomes more complex. Nevertheless, the quantitative solutions still lead to capital inflow taxes in states where the collateral constraint binds.

${ }^{29}$ See Appendix D
} 

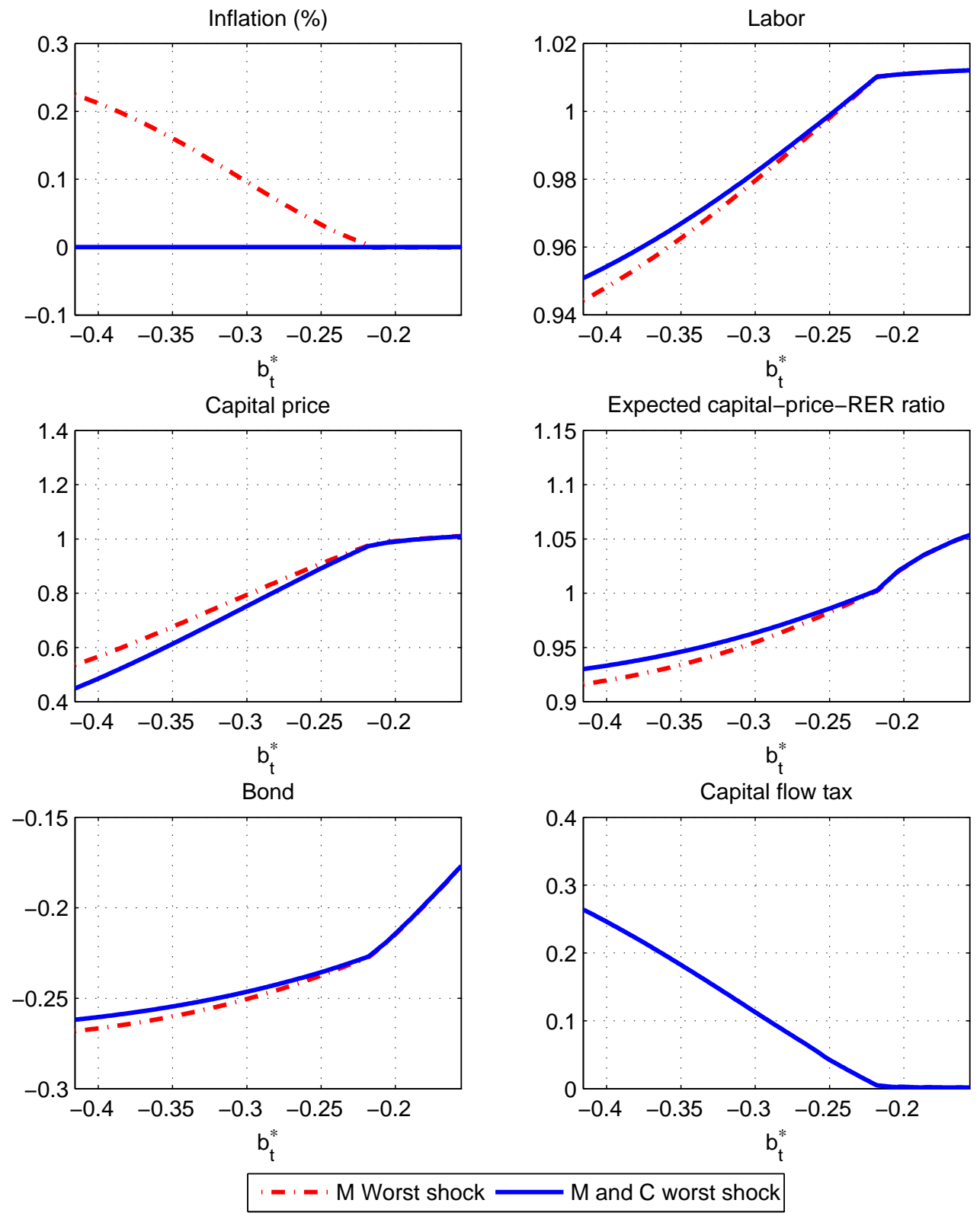

Figure 6: This graph reports policy functions under optimal monetary policy only (M), and the best responses of period $t$ Ramsey planner with both monetary and capital control instruments ( $\mathrm{M}$ and $\mathrm{C}$ ) given period $t+1$ planner choosing optimal monetary policy only. The 'worst shock' shows the case with high foreign interest rate, low domestic productivity and low domestic leverage. 
The intuition for this result depends on whether the planner has commitment or not, but the result holds in either case. Suppose the constraint is not binding today $\mu_{t}=0$ but will bind in some state tomorrow. Under discretion, a capital inflow tax will reduce current consumption by reducing borrowing; since the constraint is not binding there is no direct current collateral effect and so there is no offsetting increase in borrowing capacity that would allow higher current consumption. Moreover, the effect of a current capital inflow tax on $q_{t+1}$ through the indirect mechanism in equation (8) above has no direct benefit in terms of relaxing next period's constrained borrowing. What the planner would like to do is to increase $q_{t+2}$ but that is infeasible, since this depends on the next period's planner's actions. Hence, when the current collateral constraint does not bind, there is no benefit to a capital inflow tax. This implies that there is no scope for using capital taxes as 'macro-prudential' instruments - unlike much of the recent literature, we find that capital taxes will not be used to reduce the risk of future crises.

Surprisingly, this result also extends to the case with policy commitment. Under commitment, the current government can increase $q_{t+2}$, but it does so by using $\tau_{c, t+1}$; there is no reason to 'move early' since the current level of consumption does not need to be distorted and the future level of consumption only needs to be adjusted if the constraint actually turns out to bind. ${ }^{30}$ We show this in Appendix E. 31

This result would change if collateral is valued at $q_{t}$, for the reasons we discussed in the four-period finite horizon model - the planner now can influence the constraint in the next period directly via changing the level of debt, and so will engage in ex ante interventions even if $\mu_{c, t}=0$. That is a macro-prudential tax is then used actively in cases where a crisis is likely in the future.

Figure 6 describes the policy functions implied by the following experiment. Imagine that all future planners follow the time-consistent optimal monetary policy alone, without capital control policy. But then we allow the current planner to choose an optimal capital flow tax in addition to optimal monetary policy, which will be conditional on the net debt level and the exogenous state of the world. Note that this is not an equilibrium policy setting, since we are assuming that the current planner has a policy menu wider than do future planners. Nevertheless, the experiment illustrates the incentive to use capital inflow taxes. Figure 6 shows that the planner will raise the capital inflow tax from zero, but will keep inflation equal to the target in all states. The rise in the capital tax raises net foreign assets, increases expected

\footnotetext{
${ }^{30}$ In Jeanne and Korinek (2013), collateral is valued at the worst asset price that obtains tomorrow; ex ante policy arises in their model because the government lacks sufficient instruments to deal with the binding constraint tomorrow. Imposing their constraint in our model would not change our results, but would substantially complicate the solution due to the possibility of discontinuities in the decision rules.

${ }^{31}$ Note however that we do not characterize the full quantitative solution to the problem under policy commitment.
} 
next period capital price, relative to that in the Ramsey optimal monetary policy. The relaxation of the collateral constraint implies that intermediate imports, labor and output fall by less in the crisis than under the Ramsey optimal monetary policy. Nevertheless, Figure 6 also shows that the current capital price will fall relative to that in the Ramsey optimal monetary policy case. The time $t$ planner ignores this decline, since the collateral constraint at time $t$ is unaffected by the time $t$ capital price.

But Figure 6 does not represent the equilibrium policy functions. In equilibrium, the planner in every period will have access to the capital inflow tax. How do the results change in an equilibrium where the capital tax is utilized in all periods? Figure 7 illustrates the results for the equilibrium policy game. Here we see a striking difference from Figure 6. Both the price of capital and the expected capital price to real exchange rate ratio (which governs the degree to which the collateral constraint binds) are systematically lower than that of the optimal Ramsey monetary policy, even in states where the collateral constraint does not bind. As a corollary to this, net debt is everywhere below that of the Ramsey optimal monetary policy; the economy has systematically lower borrowing in the time-consistent equilibrium with capital taxes. Since the capital price is lower in the economy with inflow taxes, the threshold debt level which causes the collateral constraint to bind is lower in this equilibrium also.

How can the outcome with optimal capital inflow taxes differ so starkly from the economy with optimal monetary policy alone? The key feature is that in this setting, time-consistent optimal taxes are deployed in any state where the collateral constraint is binding, taking into account their ability to influence expected future asset prices, but ignoring their impact on current asset prices. In an equilibrium, this lowers asset prices uniformly, since financial markets are forward looking, and the possibility of future crisis events which trigger a rise in capital inflow taxes will reduce the equilibrium price of assets at any given period. With lower asset prices on average, at any given level of debt, the collateral constraint is more likely to be binding, conditional on the state of the world. But this in turn leads households to increase precautionary saving, and the average debt level for the economy falls.

In the out-of-equilibrium experiment discussed above, we noted that the capital inflow tax cushioned the impact of a crisis on the real economy, leading to a higher level of output, labor and intermediate imports conditional on a given level of debt, and state of the world. But in the equilibrium with time consistent inflow taxes, this situation is no longer necessarily the case. Figure 7 shows that, since the crisis is triggered at lower levels of debt, output, employment and imports may be lower than in the Ramsey monetary policy equilibrium conditional on the level of debt and the state of the world. Likewise, the real 

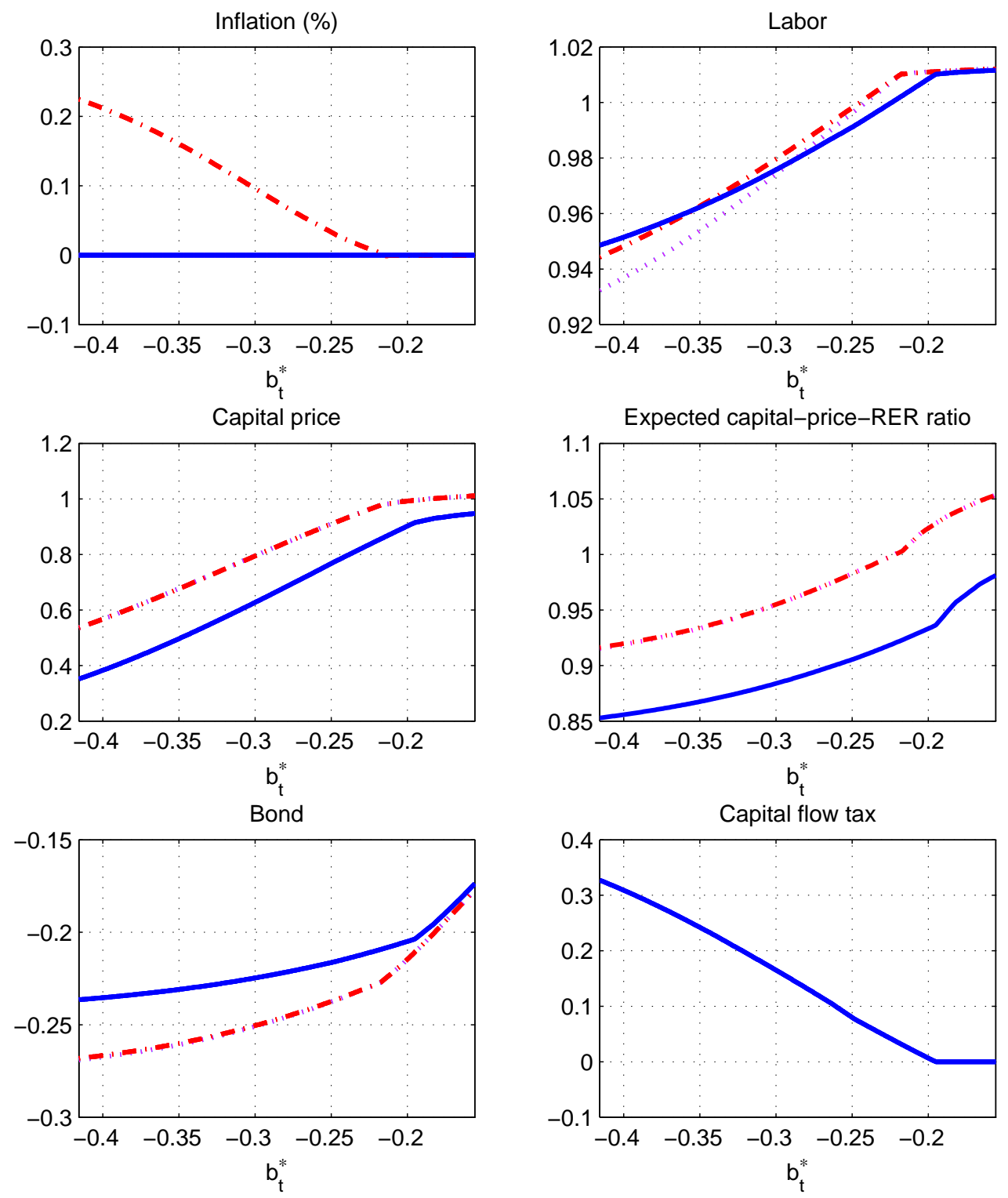

, n. CE Worst shock - - - ' M Worst shock — M and C Worst shock

Figure 7: Policy functions in the optimal monetary policy without capital controls (M), optimal monetary and capital controls ( $\mathrm{M}$ and $\mathrm{C}$ ), and the competitive equilibrium with strict inflation targeting (CE). The 'worst shock' shows the case with high foreign interest rate, low domestic productivity and low domestic leverage. 

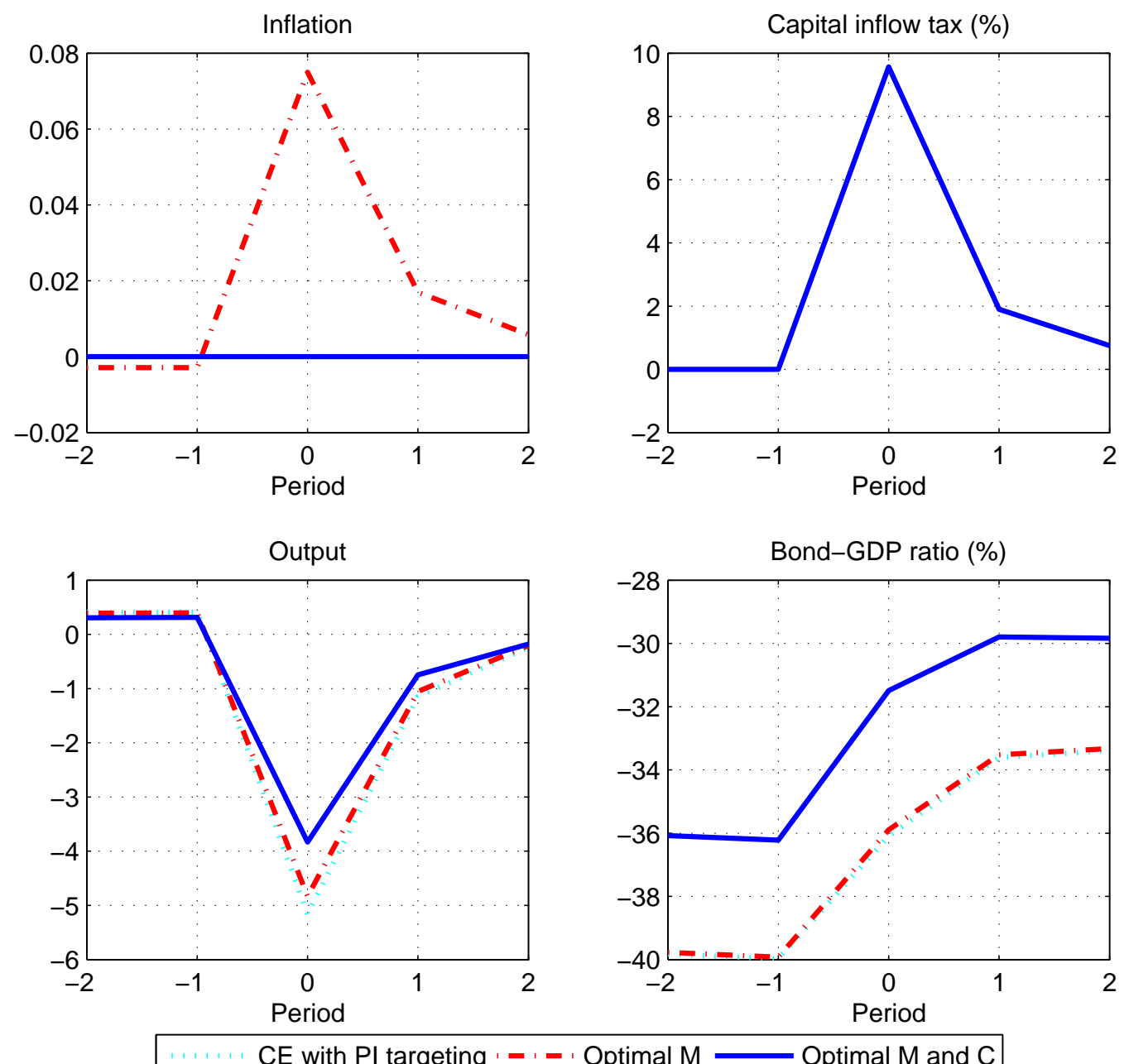

Figure 8: Event analysis in the optimal monetary policy without capital controls (M), optimal monetary and capital controls ( $\mathrm{M}$ and $\mathrm{C}$ ), and the competitive equilibrium with strict inflation targeting (CE). A typical five-period event window is chosen as: (a) no binding collateral constraints in the first two periods $t=-2,-1$, (b) binding constraint at period $t=0$ and (c) no restrictions in the last two periods $t=1,2$. The events in the figure are an average of all event series in a simulation of 200,000 periods. Each panel reports the percent deviation from the unconditional mean of that variable except for the capital inflow tax and Bond-GDP ratio. 
exchange rate is systematically higher, given a lower level of consumption and aggregate demand.

These results show that an equilibrium where optimal capital taxes are chosen without commitment may have undesirable side effects. In subsection 6.4 below we translate these differences into welfare terms. There we see that welfare may be lower in the Ramsey equilibrium with capital control policy, without commitment, than in the competitive equilibrium without optimal policy. This result is quite different than the existing literature, where capital controls, even if not fully optimal, are at least welfare-improving. ${ }^{32}$

Figure 8 illustrates the crisis event analysis in the equilibrium with capital controls, and compares this to the outcome of the competitive equilibrium and the Ramsey optimal monetary policy. The definition of a crisis is equivalent to that of Figure 4 . With capital taxes, the policy maker completely eschews active monetary policy, and maintains a strict inflation targeting at all times. Instead, as described above, when the collateral constraint binds, the policymaker imposes a capital inflow tax. The tax leads to a fall in net external debt, which allows for a relaxation of the collateral constraint (the Lagrange multiplier rises by less than in the Ramsey equilibrium with optimal monetary policy). As a result the average crisis is less severe with the capital inflow tax. ${ }^{33}$

\subsection{Welfare gains}

The lifetime utility for a representative household in the small economy, conditional on the initial debt level and exogenous shocks, reads

$$
W e l\left(b_{0}^{*}, Z_{0}\right) \equiv E_{0}\left\{\sum_{t=0}^{\infty} \beta^{t} U\left(\tilde{C}_{t}\right)\right\}=E_{0}\left\{\sum_{t=0}^{\infty} \beta^{t} \frac{\tilde{C}_{t}^{1-\sigma}-1}{1-\sigma}\right\} .
$$

We define a certainty equivalence of effective consumption $\widetilde{C\left(b_{0}^{*}, Z_{0}\right)}$ in a policy regime as

$$
W e l\left(b_{0}^{*}, Z_{0}\right)=E_{0}\left\{\sum_{t=0}^{\infty} \beta^{t} \frac{\widehat{C{\left(b_{0}^{*}, Z_{0}\right.}^{1-\sigma}-1}}{1-\sigma}\right\}=\frac{C{\widetilde{\left(b_{0}^{*}, Z_{0}\right.}}^{1-\sigma}-1}{1-\sigma} \frac{1}{1-\beta} .
$$

\footnotetext{
${ }^{32}$ A related result can be found in Young (2012), where it is optimal to 'tie the hands' of the current government by giving it fewer options; the reason there is that the government's objective function is not perfectly aligned with the private sector.

${ }^{33}$ Note that this statement is not inconsistent with the discussion above indicating that the impact of a binding constraint may be more severe with capital inflow taxes than without, since in that case we were comparing outcomes with equal levels of net external assets. In the average crisis event of Figure 8, net external assets are always higher in the economy with capital inflow taxes.
} 
Rearranging the equation yields

$$
\left.\widetilde{C\left(b_{0}^{*}, Z_{0}\right.}\right)=\left[W e l\left(b_{0}^{*}, Z_{0}\right)(1-\sigma)(1-\beta)+1\right]^{\frac{1}{1-\sigma}}
$$

Figure 9 shows the welfare gains for the "best" and "worst" states as previously described. ${ }^{34}$ The Figure shows welfare relative to that in the competitive equilibrium with strict inflation targeting, and as before, the evaluation is conditional on net external assets. The first point to note is that welfare for the Ramsey optimal monetary policy, is almost identical to that of the competitive equilibrium. This is not exactly true, since it is possible to show that the Ramsey equilibrium raises welfare very slightly relative to the competitive equilibrium, particularly for very high levels of net external debt, where crises are more likely. But the welfare gains for the optimal Ramsey monetary policy relative to strict inflation targeting are extremely small.

By contrast, the Figure shows that welfare is unambiguously lower in the time-consistent Ramsey equilibrium with both optimal monetary and capital control policy. Moreover, the welfare losses are greater, the higher is the level of net external debts.

Welfare gains are similar in shape across states, but are a bit larger in bad times. Furthermore, the relative welfare losses associated with capital controls are much larger in the bad state than in the good one.

\subsection{Moment analysis}

Table 4 illustrates the moments for a series of variables in the model across the different regimes, including the frequency with which crises occur. A crisis scenario is defined as a binding collateral constraint. The occurrence of crisis doesn’t change much across various monetary and capital control policy regimes. Compared to the competitive equilibrium with strict inflation targeting but without any capital controls, optimal monetary policy alone slightly reduces the volatility of fundamentals. With capital controls in place, the economy has a lower debt and higher consumption in the stationary equilibrium since households increase their precautionary savings. A lower debt is associated with a less severe financial crisis, which can be seen from the lower value of external finance premium. Note that capital price under capital

\footnotetext{
${ }^{34}$ Let $\tilde{C}^{j}$ denote the consumption certainty equivalence in regime $j$. Then $\left(\frac{\tilde{C}^{j}}{\tilde{C}^{i}}-1\right) \times 100$ measures the percentage increase of effective consumption in regime $i$ such that the household's welfare in regime $i$ is the same as that in regime $j$.
} 
(a) Welfare gains (\%) relative to CE (Worst state)

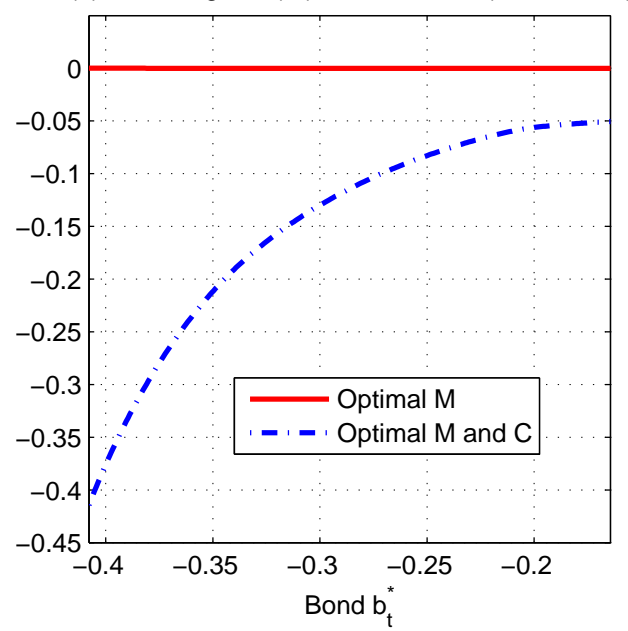

(b) Welfare gains (\%) relative to CE (Best state)

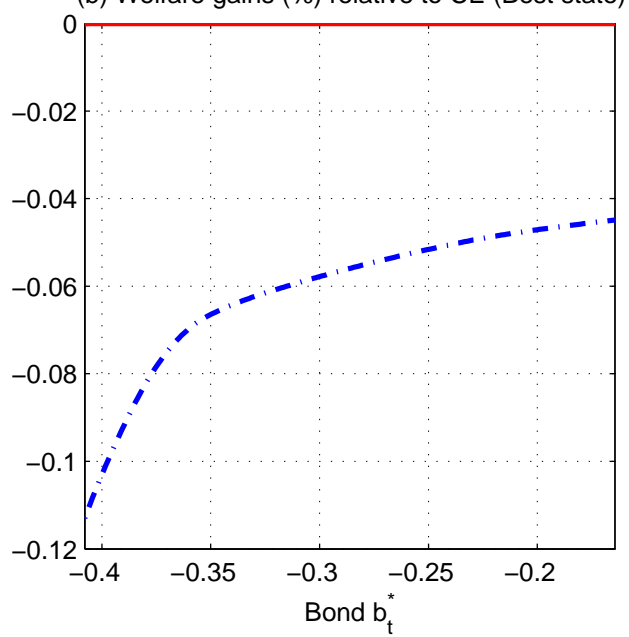

Figure 9: Welfare gains in the optimal monetary policy without capital controls (M) and optimal monetary and capital controls ( $\mathrm{M}$ and $\mathrm{C}$ ), relative to the competitive equilibrium with strict inflation targeting (CE). Welfare gains are measured by the percentage changes of certainty equivalence of effective consumption across policy regimes. The 'best shock' refers to policy functions when domestic households face low foreign interest rate, high domestic productivity and high domestic leverage, while the 'worst shock' shows the case with high foreign interest rate, low domestic productivity and low domestic leverage.

control is also lower than that without controls.

\subsection{Policy under commitment: an example}

The previous sections show that without commitment, capital inflow taxes will be imposed in a crisis, and welfare will be lower relative to a regime of optimal monetary policy without capital controls. An obvious question is what happens if there is some commitment device which binds policymakers to stick to a particular policy prescription? A full characterization of optimal policies under commitment is beyond the scope of this paper. ${ }^{35}$ Nevertheless, we know from the finite-period example in section 4 that a policymaker would subsidize capital inflows in the second period when the credit constraint binds since this will have the effect of relaxing first period credit constraints. ${ }^{36}$ Following a similar argument, we ask whether subsiding capital inflows during a crisis could improve welfare in the full dynamic model. We conjecture a simple but operational capital inflow subsidy, $\tau_{c, t}=-\varsigma \mu_{t}$, for a small positive constant $\varsigma$. This capital inflow subsidy

\footnotetext{
${ }^{35}$ Solving for the optimal policy under commitment involves a large increase in the number of state variables required for the solution for policy functions.

${ }^{36}$ Farhi and Werning (2014) study optimal capital controls under commitment in a world economy of many small open economies akin to Gali and Monacelli (2005) but with risk premium shocks. They find that dealing with a sudden stop requires a temporary subsidy on inflows and a tax on outflows.
} 
Table 4: Model moments

\begin{tabular}{|c|c|c|c|}
\hline & $\mathrm{CE}$ & $\mathrm{M}$ & $\mathrm{M}$ and $\mathrm{C}$ \\
\hline Probability of crisis (\%) & 9.0 & 9.0 & 7.8 \\
\hline \multicolumn{4}{|l|}{ Mean } \\
\hline Effective consumption & 0.4376 & 0.4376 & 0.4381 \\
\hline Output & 0.7379 & 0.7380 & 0.7385 \\
\hline Bond & -0.2926 & -0.2922 & -0.2644 \\
\hline Real exchange rate & 0.9882 & 0.9882 & 0.9881 \\
\hline Capital price & 1.0021 & 1.0021 & 0.9409 \\
\hline External finance premium (\%) & 0.77 & 0.77 & 0.44 \\
\hline \multicolumn{4}{|l|}{ Standard deviation(\%) } \\
\hline Effective consumption & 1.25 & 1.24 & 1.24 \\
\hline Output & 1.93 & 1.91 & 1.86 \\
\hline Bond & 1.56 & 1.56 & 1.51 \\
\hline Real exchange rate & 0.77 & 0.77 & 0.82 \\
\hline Capital price & 3.60 & 3.60 & 3.98 \\
\hline External finance premium & 3.58 & 3.59 & 2.15 \\
\hline \multicolumn{4}{|l|}{ Correlation with output } \\
\hline Effective consumption & 0.85 & 0.84 & 0.81 \\
\hline Output & 1.00 & 1.00 & 1.00 \\
\hline Bond & 0.16 & 0.17 & 0.20 \\
\hline Real exchange rate & 0.48 & 0.49 & 0.47 \\
\hline Capital price & 0.88 & 0.88 & 0.83 \\
\hline External finance premium & -0.40 & -0.38 & -0.31 \\
\hline
\end{tabular}

Notes: The moments are generated by a simulation of 210,000 periods with dropping the first 10,000 periods. A crisis scenario is defined as a binding collateral constraint. The column ' $\mathrm{CE}$ ' denotes the competitive equilibrium with strict inflation targeting, 'M' for optimal monetary policy without capital controls and ' $\mathrm{M}$ and $\mathrm{C}$ ' for optimal monetary and capital controls. 
is tied to the severity of a crisis. A deeper crisis requires a larger subsidy to restore borrowing capacity and therefore to maintain a higher consumption than that without subsidy. We assume that policymakers honor this capital control policy in each period. Although it is in effect only in a crisis, the capital inflow subsidy affects households' borrowing and consumption both in crises and in normal times.

Figure 10 displays policy functions under commitment with $\varsigma=0.2$ when monetary policy maintains inflation strictly equal to the targets, and the exogenous shocks lead to the worst possible state. ${ }^{37}$ Subsiding capital inflows in a crisis increases effective consumption for every given level of debt. Higher effective consumption leads to a higher current capital price and expected ratio of future capital price to future real exchange rate, which in turn expands borrowing capacity and increases the cutoff debt level that triggers the binding collateral constraint. Compared with the competitive equilibrium without capital inflow tax/subsidy, imports, employment and output are higher when capital inflow subsidy is in place. Therefore, a higher borrowing capacity and a higher effective consumption implies higher welfare for domestic households (see figure 11).

\section{$7 \quad$ Sticky Wages}

A broad message of this paper is that in open economies with financial frictions but without policy commitment monetary policy should not be combined with capital controls. But in Figure 5 above, we noted that the effect of an optimal monetary policy, relative to strict inflation targeting, was minimal. Although the optimal monetary policy calls for a sharp deviation from inflation targeting during a crisis, the crisis response under strict inflation targeting and the optimal monetary policy was relatively small. A similar message comes from the welfare evaluation. The reason for this is familiar from the literature on New Keynesian models. Nominal rigidities in prices can be relatively easily overcome by strict inflation targeting - we find that this message extends to the response to crises to a substantial extent.

But with more extensive nominal rigidities, the role for monetary policy can be much greater. Here, we illustrate this briefly, by extending our model of nominal rigidities to include both price and wage stickiness. ${ }^{38}$ The model details are delegated to the Appendix F.

\footnotetext{
${ }^{37}$ We do not explore the optimal level of $\varsigma$. For smaller or larger than $\varsigma=0.2$ capital inflow subsidies, we obtain the same qualitative results.

${ }^{38} \mathrm{~A}$ number of papers have documented the role of rigid wages, in particular downwardly rigid wages, for emerging economies during financial crises (for instance, Card and Hyslop, 1997, Schmitt-Grohe and Uribe, 2015); it is also the case that the importance of optimal monetary policy is enhanced if wages are sticky (the quantitative deviations from pure inflation targeting were quite small in the previous section and the welfare consequences were negligible).
} 

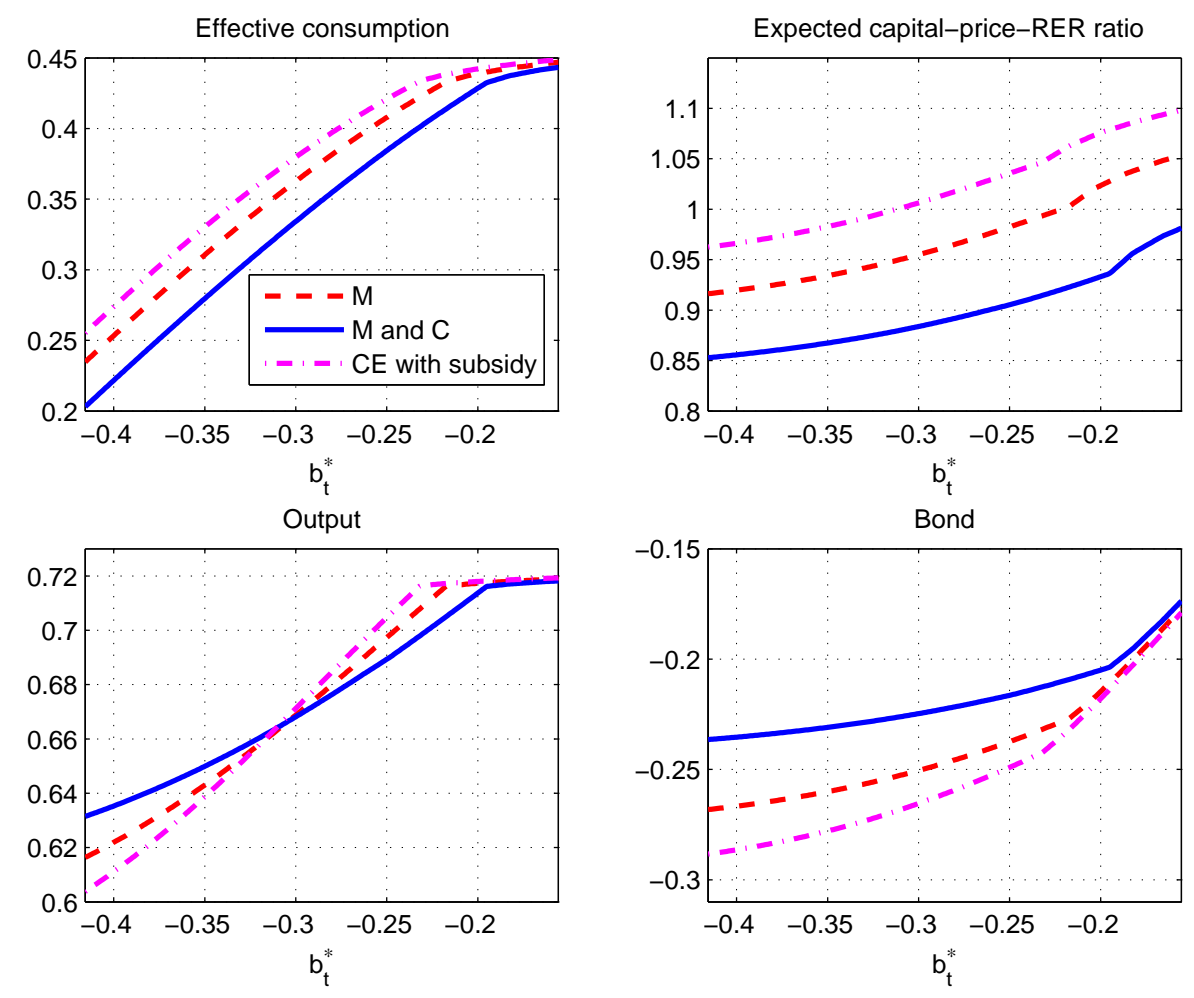

Figure 10: Policy functions in the optimal monetary policy without capital controls (M), optimal monetary and capital controls ( $\mathrm{M}$ and $\mathrm{C}$ ), and a competitive equilibrium with strict inflation targeting and an ad hoc statecontingent capital inflow subsidy $\tau_{c, t}=-0.2 \mu_{t}$ (CE with subsidy), when domestic households face high foreign interest rate, low domestic productivity and low domestic leverage. 
(a) Welfare gains (\%) relative to CE (Worst state)

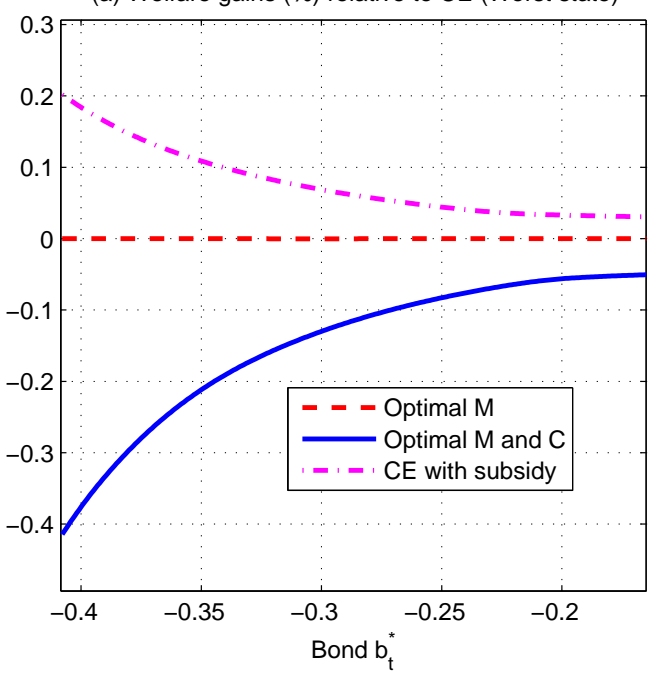

(b) Welfare gains (\%) relative to CE (Best state)

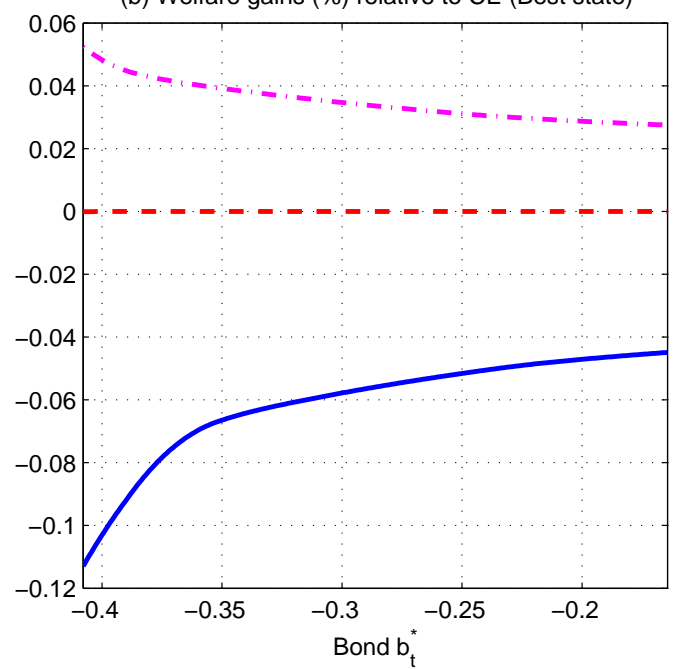

Figure 11: Welfare gains in the optimal monetary policy without capital controls (M), optimal monetary and capital controls ( $\mathrm{M}$ and $\mathrm{C}$ ), and a competitive equilibrium with strict inflation targeting and an ad hoc statecontingent capital inflow subsidy $\tau_{c, t}=-0.2 \mu_{t}$ (CE with subsidy), relative to the competitive equilibrium with strict inflation targeting $(\mathrm{CE})$. Welfare gains are measured by the percentage changes of certainty equivalence of effective consumption across policy regimes. The 'best shock' refers to policy functions when domestic households face low foreign interest rate, high domestic productivity and high domestic leverage, while the 'worst shock' shows the case with high foreign interest rate, low domestic productivity and low domestic leverage.

Figure 12 reports variables of interest in a typical event analysis and figure 13 shows the welfare gains across policy regimes. With downward nominal wage rigidity, the competitive equilibrium with strict inflation targeting suffers a large decline in employment and output. Under optimal monetary policy, the monetary authority creates inflation and devalues the domestic currency to restore domestic employment and output. The effect of monetary policy is substantial compared to the case without downward nominal wage rigidity. Figure 12 shows that output losses can be reduced by one half under the optimal monetary policy in crisis. ${ }^{39}$ When output is less depressed under optimal monetary policy, households repay a larger amount of debt in order to smooth consumption. In terms of welfare, households are significantly and uniformly better off than in the competitive equilibrium with strict inflation targeting (see panel (a)-(b) in figure 13).

When both monetary policy and capital controls are in place, again without commitment, the policy maker sets a positive capital inflow tax, 9.5\%, in the peak period of a crisis and imposes zero capital controls out of crisis. However, unlike the previous case, where active monetary policy was not combined

\footnotetext{
${ }^{39}$ Schmitt-Grohe and Uribe (2015) and Na, Schmitt-Grohé, Uribe and Yue (2014) also show that depreciating domestic currency can significantly reduce unemployment and output losses in crisis when nominal wages are downwardly rigid.
} 

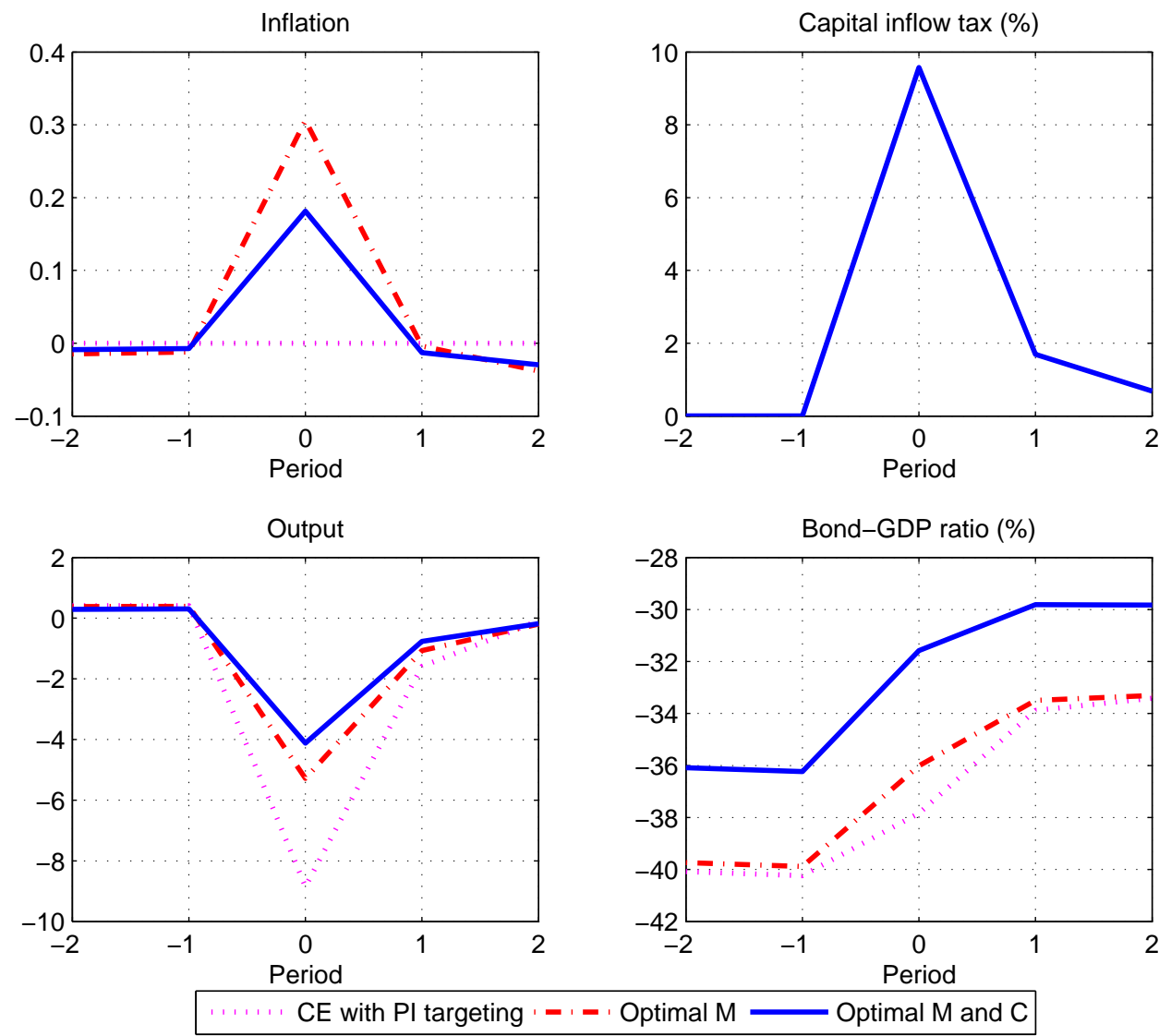

Figure 12: Event analysis in a model with sticky prices and sticky wages for the optimal monetary policy without capital controls $(\mathrm{M})$, optimal monetary and capital controls ( $\mathrm{M}$ and $\mathrm{C}$ ), and the competitive equilibrium with strict inflation targeting (CE). A typical five-period event window is chosen as: (a) no binding collateral constraints in the first two periods $t=-2,-1$, (b) binding constraint at period $t=0$ and (c) no restrictions in the last two periods $t=1,2$. The events in the figure are an average of all event series in a simulation of 200,000 periods. Each panel reports the percent deviation from the unconditional mean of that variable except for the capital inflow tax and Bond-GDP ratio. 
(a)

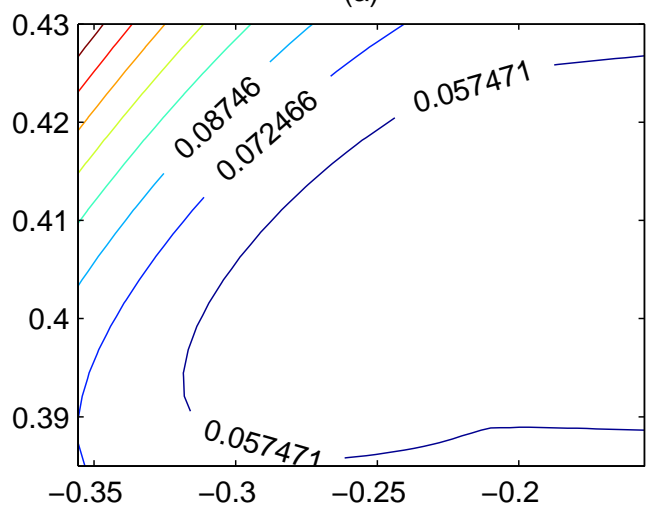

(c)

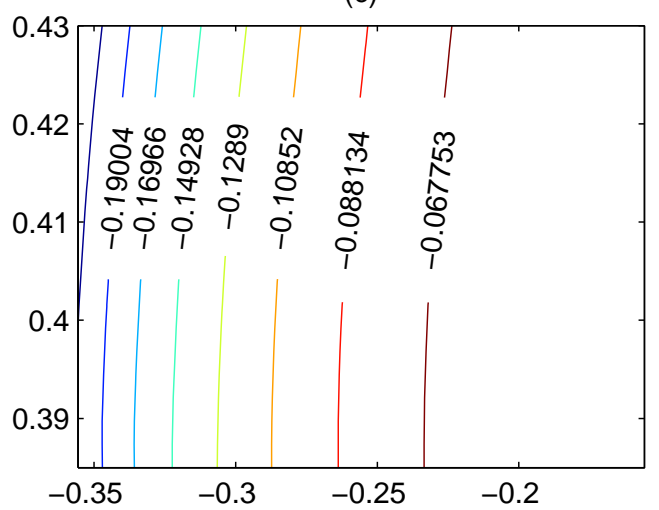

(b)

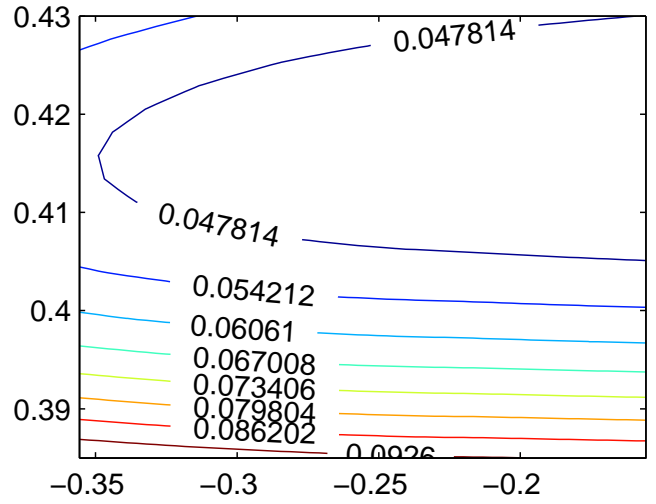

(d)

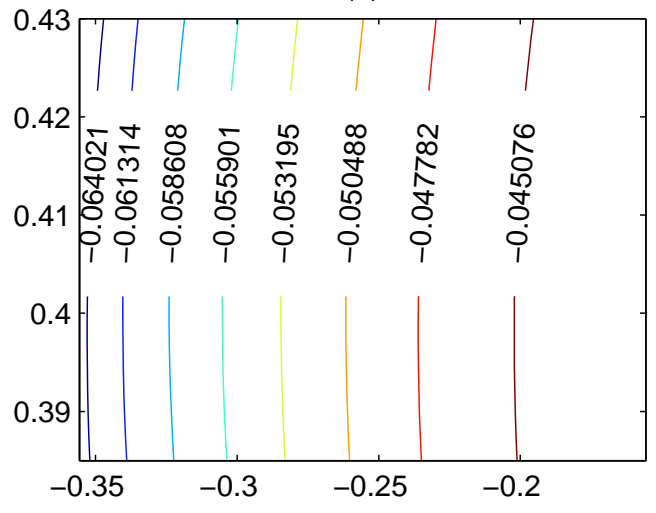

Figure 13: Welfare gains in a model with sticky prices and sticky wages for the optimal monetary policy without capital controls (M) and optimal monetary and capital controls ( $\mathrm{M}$ and $\mathrm{C}$ ), relative to the competitive equilibrium with strict inflation targeting $(\mathrm{CE})$. Welfare gains are measured by the percentage change of effective consumption equivalence across policy regimes. The vertical axis is the past real wage $w_{t-1}$ and the horizontal axis stands for debt level $b_{t}^{*}$. Panel (a)-(b) are for $\mathrm{M}$ policy relative to the $\mathrm{CE}$ with strict price inflation targeting under the worst and best state respectively, and (c)-(d) for $\mathrm{M}$ and $\mathrm{C}$ policy relative to $\mathrm{M}$ policy under the worst and best state respectively. The 'best shock' refers to policy functions when domestic households face low foreign interest rate, high domestic productivity and high domestic leverage, while the 'worst shock' shows the case with high foreign interest rate, low domestic productivity and low domestic leverage. 
with capital controls in a crisis, the optimal monetary now combines both capital controls and monetary policy to react to a crisis. Monetary policy generates inflation and currency devaluation to dampen the adverse shocks to the economy (see figure 12). Again, due to the time consistency problem, higher capital controls lead to a lower welfare for households (see panel (c)-(d) in figure 13).

\section{Conclusion}

This paper has studied the optimal conduct of monetary policy and capital controls during a "Sudden Stop" engineered by a binding collateral constraint. We highlight several main results here in the conclusion. First, inflation targeting is optimal outside Sudden Stops, but during a financial crisis it is optimal to generate some domestic inflation; this result comes from the absence of a tool designed specifically to deal with the underlying causes of the crisis (the financial accelerator). Second, capital controls are suboptimal but will be used in a time-consistent equilibrium, and therefore should not be placed under the control of the monetary authority. Third, the case for ex ante intervention is heavily dependent on arbitrary choices regarding the valuation of collateral and therefore could be related to the optimal choice of financial regulation.

There are many extensions that we plan to consider going forward. In particular, we plan to use the model to study the optimal use of monetary and capital control policy in the presence of a fixed exchange rate - the 'dilemma-not-trilemma' argument currently playing out in the literature states that monetary policy is severely weakened by the absence of capital controls even if exchange rates are fixed. Exactly what this statement means is unclear - does it mean that interventions must be larger to achieve the same goals, or does it mean that the optimal adjustment is smaller, or perhaps something else entirely? Since a fixed exchange rate may inhibit some of the adverse movements in the value of collateral, our model may imply that pegs are occasionally useful.

\section{References}

Aguiar, Mark, and Gita Gopinath (2007) 'Emerging Market Business Cycles: the Cycle is the Trend.' Journal of Political Economy 115, 69-102 
Aruoba, S. Boragan, Pablo Cuba-Borda, and Frank Schorfheide (2013) 'Macroeconomic Dynamics Near the ZLB: A Tale of Two Countries.' Working Paper 19248, National Bureau of Economic Research, July

Bacchetta, Philippe, and Eric van Wincoop (2000) 'Capital Flows to Emerging Markets: Liberalization, Overshooting, and Volatility.' In 'Capital Flows and the Emerging Economies: Theory, Evidence, and Controversies' NBER Chapters (National Bureau of Economic Research, Inc) pp. 61-98

Backus, David K, Patrick J Kehoe, and Finn E Kydland (1992) 'International Real Business Cycles.' Journal of Political Economy 100(4), 745-75

Barro, Robert J., and David B. Gordon (1983) 'Rules, Discretion and Reputation in a Model of Monetary Policy.' Journal of Monetary Economics 12(1), 101 - 121

Benhabib, Jess, and Aldo Rustichini (1997) 'Optimal Taxes without Commitment.' Journal of Economic Theory $77(2), 231-259$

Benigno, Gianluca, Huigang Chen, Chris Otrok, Alessandro Rebucci, and Eric Young (2012) 'Optimal Policy for Macro-Financial Stability.' CEP Discussion Papers dp1172, Centre for Economic Performance, LSE, October

Benigno, Gianluca, Huigang Chen, Christopher Otrok, Alessandro Rebucci, and Eric R. Young (2013) 'Financial Crises and Macro-prudential Policies.' Journal of International Economics 89(2), 453-470

Benigno, Gianluca, Huigang Chen, Christopher Otrok, Alessandro Rebucci, and Eric R Young (2014) 'Optimal Capital Controls and Real Exchange Rate Policies: A Pecuniary Externality Perspective.' CEPR Discussion Papers 9936, C.E.P.R. Discussion Papers, April

Bianchi, Javier (2011) 'Overborrowing and Systemic Externalities in the Business Cycle.' American Economic Review 101(7), 3400-3426

Bianchi, Javier, and Enrique G. Mendoza (2010) 'Overborrowing, Financial Crises and 'Macro-prudential' Taxes.' NBER Working Papers 16091, National Bureau of Economic Research, Inc, June

_ (2013) 'Optimal Time-Consistent Macroprudential Policy.' NBER Working Papers 19704, National Bureau of Economic Research, Inc, December 
Braggion, Fabio, Lawrence J. Christiano, and Jorge Roldos (2009) 'Optimal Monetary Policy in a 'Sudden Stop'.' Journal of Monetary Economics 56(4), 582 - 595

Broner, Fernando A., Guido Lorenzoni, and Sergio L. Schmukler (2013a) 'Why Do Emerging Economies Borrow Short Term?' Journal of the European Economic Association 11, 67-100

Broner, Fernando, Tatiana Didier, Aitor Erce, and Sergio L. Schmukler (2013b) 'Gross Capital Flows: Dynamics and Crises.' Journal of Monetary Economics 60(1), 113 - 133. Carnegie-NYU-Rochester Conference

Bruno, Valentina, and Hyun Song Shin (2015a) 'Capital Flows and the Risk-taking Channel of Monetary Policy.' Journal of Monetary Economics 71(C), 119-132

Bruno, Valentina, and Hyun Song Shin (2015b) 'Cross-Border Banking and Global Liquidity.' Review of Economic Studies 82(2), 535-564

Calvo, Guillermo A (1978) 'On the Time Consistency of Optimal Policy in a Monetary Economy.' Econometrica 46(6), 1411-28

Card, David, and Dean Hyslop (1997) 'Does Inflation Grease the Wheels of the Labor Market?' In 'Reducing inflation: Motivation and strategy' (University of Chicago Press) pp. 71-122

Cespedes, Luis Felipe, Roberto Chang, and Andres Velasco (2004) 'Balance Sheets and Exchange Rate Policy.' American Economic Review 94(4), 1183-1193

Chen, Haipeng (Allan), Daniel Levy, Sourav Ray, and Mark Bergen (2008) 'Asymmetric Price Adjustment in the Small.' Journal of Monetary Economics 55(4), 728-737

Christiano, Lawrence J., Martin Eichenbaum, and Charles L. Evans (2005) 'Nominal Rigidities and the Dynamic Effects of a Shock to Monetary Policy.' Journal of Political Economy 113(1), 1-45

Coleman, Wilbur John (1990) 'Solving the Stochastic Growth Model by Policy-Function Iteration.' Journal of Business and Economic Statistics 8(1), 27-29

Costinot, Arnaud, Guido Lorenzoni, and Ivan Werning (2014) 'A Theory of Capital Controls as Dynamic Terms-of-Trade Manipulation.' Journal of Political Economy 122(1), 77 - 128 
Devereux, Michael B., and Changhua Yu (2014) 'International Financial Integration and Crisis Contagion.' NBER Working Papers 20526, National Bureau of Economic Research, Inc

Devereux, Michael B., Philip R. Lane, and Juanyi Xu (2006) 'Exchange Rates and Monetary Policy in Emerging Market Economies.' The Economic Journal 116(511), 478-506

Dong, Bingbing (2015) 'Forward Guidance and Optimal Credible Monetary Policy.' Manuscript, University of Virginia

Eaves, B. Curtis, and Karl Schmedders (1999) 'General Equilibrium Models and Homotopy Methods.' Journal of Economic Dynamics and Control 23(9-10), 1249-1279

Farhi, Emmanuel, and Ivan Werning (2012) 'Dealing with the Trilemma: Optimal Capital Controls with Fixed Exchange Rates.' NBER Working Papers 18199, National Bureau of Economic Research, Inc, June _ (2014) 'Dilemma not Trilemma? Capital Controls and Exchange Rates with Volatile Capital Flows.' IMF Economic Review 62(4), 569-605

Farhi, Emmanuel, Christopher Sleet, Ivan Werning, and Sevin Yeltekin (2012) 'Non-linear capital taxation without commitment.' Review of Economic Studies 79(4), 1469-1493

Fornaro, Luca (2015) 'Financial Crises and Exchange Rate Policy.' Journal of International Economics 95(2), 202-215

Frankel, Jeffrey (2010) 'Monetary Policy in Emerging Markets.' In Handbook of Monetary Economics, ed. Benjamin M. Friedman and Michael Woodford, vol. 3 of Handbook of Monetary Economics (Elsevier) chapter 25 , pp. $1439-1520$

Fratzscher, Marcel (2012) 'Capital Flows, Push versus Pull Factors and the Global Financial Crisis.' Journal of International Economics 88(2), 341 - 356. \{NBER\} Global

Gali, Jordi (2015) Monetary Policy, Inflation, and the Business Cycle: An Introduction to the New Keynesian Framework (the Second Edition, Princeton University Press)

Gali, Jordi, and Tommaso Monacelli (2005) 'Monetary Policy and Exchange Rate Volatility in a Small Open Economy.' The Review of Economic Studies 72(3), 707-734 
Gertler, Mark, Simon Gilchrist, and Fabio M. Natalucci (2007) 'External Constraints on Monetary Policy and the Financial Accelerator.' Journal of Money, Credit and Banking 39(2/3), pp. 295-330

Graham, John R., Mark T. Leary, and Michael R. Roberts (2014) 'A Century of Capital Structure: the Leveraging of Corporate America.' Journal of Financial Economics pp. -

Greenwood, Jeremy, Zvi Hercowitz, and Gregory W Huffman (1988) 'Investment, Capacity Utilization, and the Real Business Cycle.' American Economic Review 78(3), 402-17

Hanson, Gordon H. (2012) 'The Rise of Middle Kingdoms: Emerging Economies in Global Trade.' Journal of Economic Perspectives 26(2), 41-64

Iacoviello, Matteo (2005) 'House Prices, Borrowing Constraints, and Monetary Policy in the Business Cycle.' The American Economic Review 95(3), 739-764

IMF (2014) Regional Economic Outlook: Asia and Pacific World Economic and Financial Surveys, International Monetary Fund, Washington, D.C., 20090, USA

Jeanne, Olivier (2003) 'Why Do Emerging Economies Borrow in Foreign Currency?' IMF Working Papers 03/177, International Monetary Fund, September

Jeanne, Olivier, and Anton Korinek (2010) 'Excessive Volatility in Capital Flows: A Pigouvian Taxation Approach.' American Economic Review 100(2), 403-07

_ (2013) 'Macroprudential Regulation Versus Mopping Up After the Crash.' NBER Working Papers 18675, National Bureau of Economic Research, Inc, January

Kaminsky, Graciela L., Carmen M. Reinhart, and Carlos A. Vegh (2005) 'When It Rains, It Pours: Procyclical Capital Flows and Macroeconomic Policies.' In 'NBER Macroeconomics Annual 2004, Volume 19’ NBER Chapters (National Bureau of Economic Research, Inc) pp. 11-82

Katagiri, Mitsuru, Ryo Kato, and Takayuki Tsuruga (2013) 'Managing Financial Crises: Lean or Clean?' Technical Report

Khan, Hashmat (2005) 'Price-setting Behaviour, Competition, and Markup Shocks in the New Keynesian Model.' Economics Letters 87(3), 329-335 
Kim, Jinill, and Francisco J. Ruge-Murcia (2009) 'How Much Inflation is Necessary to Grease the Wheels?' Journal of Monetary Economics 56(3), 365-377

Kiyotaki, Nobuhiro, and John Moore (1997) 'Credit Cycles.' Journal of Political Economy 105(2), 211-48

Klein, Paul, Per Krusell, and Jose-Victor Rios-Rull (2008) 'Time-Consistent Public Policy.' Review of Economic Studies 75(3), 789-808

Korinek, Anton (2011) 'The New Economics of Prudential Capital Controls: A Research Agenda.' IMF Economic Review, International Monetary Fund

Korinek, Anton, and Alp Simsek (2013) 'Liquidity Trap and Excessive Leverage.' Working paper, MIT, October

Kydland, Finn E, and Edward C Prescott (1977) 'Rules Rather Than Discretion: The Inconsistency of Optimal Plans.' Journal of Political Economy 85(3), 473-91

Lane, Philip R., and Gian Maria Milesi-Ferretti (2008) 'The Drivers of Financial Globalization.' The American Economic Review 98(2), pp. 327-332

Levy-Yeyati, Eduardo, and Federico Sturzenegger (2005) 'Classifying Exchange Rate Regimes: Deeds vs. Words.' European Economic Review 49(6), 1603-1635

Mendoza, Enrique G (2010) 'Sudden Stops, Financial Crises, and Leverage.' American Economic Review 100(5), 1941-1966

Na, Seunghoon, Stephanie Schmitt-Grohé, Martin Uribe, and Vivian Z Yue (2014) 'A Model of the Twin Ds: Optimal Default and Devaluation.' Technical Report, National Bureau of Economic Research

Passari, Evgenia, and Helene Rey (2015) 'Financial Flows and the International Monetary System.' The Economic Journal 125(584), 675-698

Peltzman, Sam (2000) 'Prices Rise Faster than They Fall.' Journal of Political Economy 108(3), 466-502

Reinhart, Carmen, and Vincent Reinhart (2009) 'Capital Flow Bonanzas: an Encompassing View of the Past and Present.' In 'NBER International Seminar on Macroeconomics 2008' NBER Chapters (National Bureau of Economic Research, Inc) pp. 9-62 
Rey, Helene (2015) 'Dilemma not Trilemma: the Global Financial Cycle and Monetary Policy Independence.' Working Paper 21162, National Bureau of Economic Research, May

Rotemberg, Julio J (1982) 'Monopolistic Price Adjustment and Aggregate Output.' Review of Economic Studies 49(4), 517-31

Rudebusch, Glenn D. (2002) 'Term Structure Evidence on Interest Rate Smoothing and Monetary Policy Inertia.' Journal of Monetary Economics 49(6), 1161 - 1187

_ (2006) 'Monetary Policy Inertia: Fact or Fiction?' International Journal of Central Banking 2(4), 85-135

Schittkowski, Klaus (2014) 'NLPQLP: A fortran implementation of a sequential quadratic programming algorithm with distributed and non-monotone line search - user's guide, version 4.2.' Report, Department of Computer Science, University of Bayreuth

Schmitt-Grohe, Stephanie, and Martin Uribe (2015) 'Downward Nominal Wage Rigidity, Currency Pegs, and Involuntary Unemployment.' forthcoming, Journal of Political Economy

Tauchen, George, and Robert Hussey (1991) 'Quadrature-Based Methods for Obtaining Approximate Solutions to Nonlinear Asset Pricing Models.' Econometrica 59(2), 371-96

The Economist (2013) 'Just in Case.' The Economist October 12, http://www.economist.com/news/specialreport/21587383-capital-controls-are-back-part-many-countries-financial-armoury-just-case

Uribe, Martin, and Vivian Z. Yue (2006) 'Country Spreads and Emerging Countries: Who Drives Whom?' Journal of International Economics 69(1), 6-36

Varian, Hal R (1975) 'A Bayesian Approach to Real Estate Assessment.' Studies in Bayesian Econometrics and Statistics in Honor of Leonard J. Savage pp. 195-208

Young, Eric R. (2012) 'Robust Policymaking in the Face of Sudden Stops.' Journal of Monetary Economics $59(5), 512-527$ 


\section{Not for Publication Appendices}

\section{A A system of competitive equilibrium conditions}

A system of competitive equilibrium conditions are listed as follows.

$$
\begin{aligned}
& w_{t}=\chi L_{t}^{\nu}, \\
& q_{t}=\mu_{t} \kappa_{t} e_{t} E_{t}\left\{\frac{q_{t+1}}{e_{t+1}}\right\}+E_{t}\left\{\beta \frac{U_{c}(t+1)}{U_{c}(t)}\left(r_{K, t+1}+q_{t+1}\right)\right\}, \\
& 1-\tau_{c, t}=\mu_{t} R_{t+1}^{*}+E_{t}\left\{\beta \frac{U_{c}(t+1)}{U_{c}(t)} \frac{e_{t+1}}{e_{t}} R_{t+1}^{*}\right\}, \\
& 1=E_{t}\left\{\beta \frac{U_{c}(t+1)}{U_{c}(t)} \frac{R_{t+1}}{\pi_{t+1}}\right\}, \\
& \left(1+\tau_{N, t}\right) e_{t}\left(1+\mu_{t} \vartheta\right) Y_{F, t}=\alpha_{F} p_{M, t} Y_{t}, \\
& w_{t} L_{t}=\alpha_{L} p_{M, t} Y_{t}, \\
& r_{K, t} K_{t}=\alpha_{K} p_{M, t} Y_{t}, \\
& e_{t} \mu_{t}\left[\kappa_{t} E_{t}\left(\frac{q_{t+1} K_{t+1}}{e_{t+1}}\right)+b_{t+1}^{*}-\vartheta Y_{F, t}\right]=0 \text {, } \\
& \mu_{t} \geq 0 \\
& \kappa_{t} E_{t}\left(\frac{q_{t+1} K_{t+1}}{e_{t+1}}\right)+b_{t+1}^{*}-\left(1+\tau_{N, t}\right) \vartheta Y_{F, t} \geq 0 \\
& Y_{t}=A_{t}\left(Y_{F, t}\right)^{\alpha_{F}} L_{t}^{\alpha_{L}} K_{t}^{\alpha_{K}}, \\
& Y_{t}\left[\left(1+\tau_{H}\right)(1-\theta)+\theta p_{M, t}\right]-\phi_{P} Y_{t} \pi_{t} \frac{\exp \left(\gamma\left(\pi_{t}-\pi\right)\right)-1}{\gamma} \\
& +E_{t}\left[\beta \frac{U_{c}(t+1)}{U_{c}(t)} \phi_{P} \pi_{t+1} Y_{t+1} \frac{\exp \left(\gamma\left(\pi_{t+1}-\pi\right)\right)-1}{\gamma}\right]=0 . \\
& Y_{t}\left[1-\phi\left(\pi_{t}\right)\right]=C_{t}+e_{t}^{\rho} \zeta_{t}^{*}+\left(K_{t+1}-K_{t}\right) q_{t}, \\
& \left(e_{t}\right)^{\rho} \zeta_{t}^{*}-Y_{F, t} e_{t}=\left(\frac{b_{t+1}^{*}}{R_{t+1}^{*}}-b_{t}^{*}\right) e_{t}, \\
& K_{t+1}=K_{t}=1 \\
& \text { Fiscal policies: } \tau_{H}=\frac{1}{\theta-1}, \tau_{N, t}=\frac{1}{\rho-1}
\end{aligned}
$$

Monetary and capital control policies: $\tau_{c, t}, R_{t+1}$

\section{B Equilibrium conditions in the simplified model}

This appendix describes the equilibrium conditions under various policy regimes in the four-period simplified model. We first discuss the competitive equilibrium, then the first best allocation. Allocations under full commitment and under discretion are in the last two subsections. 


\section{B.1 The competitive equilibrium}

In the competitive equilibrium, firm-households at each period choose consumption, borrowing, capital stock, labor and imports, given capital price and capital control policies. Observe that there's no financial friction in the last period. Labor supply, imports and output are exogenously-determined in period $t=3$

$$
\begin{gathered}
L_{3}=\left[A\left(\frac{\alpha_{L}}{\chi}\right)^{1-\alpha_{F}}\left(\frac{\alpha_{F}}{p_{F}^{*}}\right)^{\alpha_{F}}\right]^{\frac{1}{(1+\nu)\left(1-\alpha_{F}\right)-\alpha_{L}}} \\
Y_{F, 3}=\chi L_{3}^{1+\nu} \frac{\alpha_{F}}{\alpha_{L} p_{F}^{*}} \\
Y_{3}=A\left(Y_{F, 3}\right)^{\alpha_{F}} L_{3}^{\alpha_{L}} \\
r_{K, 3} K_{3}=\alpha_{K} Y_{3}
\end{gathered}
$$

Capital price is zero $q_{3}=0$ since it is fully depreciated after production, and consumption only depends on the inherited debts

$$
c_{3}=b_{3}^{*}+Y_{3}-p_{F}^{*} Y_{F, 3} .
$$

At period $t=0,1$, the optimality conditions are as follows

$$
\begin{gathered}
\mu_{t}\left[\kappa_{t} E_{t}\left(q_{t+1} k_{t+1}\right)+b_{t+1}^{*}-\vartheta p_{F}^{*} Y_{F, t}\right]=0, \\
\kappa_{t} E_{t}\left(q_{t+1} k_{t+1}\right) \geq-b_{t+1}^{*}+\vartheta p_{F}^{*} Y_{F, t} \\
\mu_{t} \geq 0 \\
q_{t}=E_{t}\left\{\beta \frac{U_{c}(t+1)}{U_{c}(t)}\left(r_{K, t+1}+q_{t+1}\right)\right\}+\mu_{t} \kappa_{t} E_{t}\left\{q_{t+1}\right\}, \\
1-\tau_{c, t}=\mu_{t} R^{*}+E_{t}\left\{\beta \frac{U_{c}(t+1)}{U_{c}(t)} R^{*}\right\}, \\
p_{F}^{*}\left(1+\mu_{t} \vartheta\right) Y_{F, t}=\alpha_{F} Y_{t}, \\
L_{t}=\left[\frac{\alpha_{L} A Y_{F, t}^{\alpha_{F}}}{\chi}\right]^{\frac{1}{1+\nu-\alpha_{L}}}, \\
r_{K, t} K_{t}=\alpha_{K} Y_{t}, \\
Y_{t}=A\left(Y_{F, t}\right)^{\alpha_{F}} L_{t}^{\alpha_{L}} K_{t}^{\alpha_{K}}, \\
Y_{t}-Y_{F, t} p_{F}^{*}=c_{t}+\left(\frac{b_{t+1}^{*}}{R^{*}}-b_{t}^{*}\right), \\
K_{t+1}=K_{t}=k_{t+1}=1
\end{gathered}
$$

At period $t=2$, the optimality conditions can be written as

$$
\begin{gathered}
\mu_{t}\left[\kappa_{t} \bar{q}+b_{t+1}^{*}-\vartheta p_{F}^{*} Y_{F, t}\right]=0, \\
\kappa_{t} \bar{q} \geq-b_{t+1}^{*}+\vartheta p_{F}^{*} Y_{F, t} \\
\mu_{t} \geq 0
\end{gathered}
$$




$$
\begin{gathered}
q_{t}=E_{t}\left\{\beta \frac{U_{c}(t+1)}{U_{c}(t)}\left(r_{K, t+1}+q_{t+1}\right)\right\} \\
1-\tau_{c, t}=\mu_{t} R^{*}+E_{t}\left\{\beta \frac{U_{c}(t+1)}{U_{c}(t)} R^{*}\right\} \\
p_{F}^{*}\left(1+\mu_{t} \vartheta\right) Y_{F, t}=\alpha_{F} Y_{t}, \\
L_{t}=\left[\frac{\alpha_{L} A Y_{F, t}^{\alpha_{F}}}{\chi}\right]^{\frac{1}{1+\nu-\alpha_{L}}}, \\
r_{K, t} K_{t}=\alpha_{K} Y_{t}, \\
Y_{t}=A\left(Y_{F, t}\right)^{\alpha_{F}} L_{t}^{\alpha_{L}} K_{t}^{\alpha_{K}}, \\
Y_{t}-Y_{F, t} p_{F}^{*}=c_{t}+\left(\frac{b_{t+1}^{*}}{R^{*}}-b_{t}^{*}\right), \\
K_{t+1}=K_{t}=k_{t+1}=1
\end{gathered}
$$

Now twelve equations (B.1)-(B.4) and (B.5)-(B.8) can sole for twelve variables $\left\{q_{t}, Y_{F, t}, \mu_{t}, b_{t+1}^{*}\right\}$ with $t=0,1,3$, given the initial state $b_{0}^{*}$ and government policy $\tau_{c, t}$. Other variables can be solved based on the remaining equations.

\section{B.2 The first best allocation}

The only friction in this simplified model is the collateral constraint and the only uncertainty comes from leverage shocks. Both of these originate from the financial sector. If there were no financial frictions, leverage shocks would not affect aggregate variables and financial variables at all. As a benchmark, we first consider an economy without financial frictions, where collateral constraints are always slack in every period. Note that without credit constraints, labor, imports and production are completely exogenous and the economy collapses to an endowment economy. In

the current case with only leverage shocks, firm-households' labor income and profits in all periods are constant as in period $t=3$. The optimality conditions read

$$
\begin{gathered}
1=\beta \frac{U_{c}(t+1)}{U_{c}(t)} R^{*}, t=0,1,2 \\
c_{t}=Y_{t}-Y_{F, t} p_{F}^{*}-\left(\frac{b_{t+1}^{*}}{R^{*}}-b_{t}^{*}\right), t=0,1,2 \\
c_{3}=Y_{3}-p_{F}^{*} Y_{F, 3}+b_{3}^{*} .
\end{gathered}
$$

Now we have seven unknowns $\left\{c_{t}, b_{t+1}^{*}\right\}$ with $t=0,1,2$, and $c_{3}$ in seven equations.

\section{B.3 Equilibrium under commitment}

We now turn to the optimal capital control policies. Under commitment, policy makers in each period can commit themselves to a policy path $\tau_{c, t}$ with $t=0,1$, specified at the initial period $t=0$. They choose such a policy path to maximize the lifetime utility of a representative household subject to the implementability constraints. The social planner under commitment is defined as follows.

$$
\max _{\Xi} E_{0}\left\{\sum_{t=0}^{t=3} \beta^{t} U\left(c_{t}, l_{t}\right)\right\}
$$


with

$$
\Xi \equiv\left\{q_{t}, Y_{F, t}, \mu_{t}, b_{t+1}^{*}\right\}_{t=0,1,2}
$$

subject to

$$
\begin{gathered}
\mu_{t}\left[\kappa_{t} E_{t}\left(q_{t+1}\right)+b_{t+1}^{*}-\vartheta p_{F}^{*} Y_{F, t}\right]=0, t=0,1 \\
\kappa_{t} E_{t}\left(q_{t+1}\right) \geq-b_{t+1}^{*}+\vartheta p_{F}^{*} Y_{F, t}, t=0,1 \\
\mu_{t} \geq 0, t=0,1 \\
\mu_{2}\left[\kappa_{2} \bar{q}+b_{3}^{*}-\vartheta p_{F}^{*} Y_{F, 2}\right]=0, \\
\kappa_{2} \bar{q} \geq-b_{3}^{*}+\vartheta p_{F}^{*} Y_{F, 2} \\
\mu_{2} \geq 0 \\
q_{t}=E_{t}\left\{\beta \frac{U_{c}(t+1)}{U_{c}(t)}\left(r_{K, t+1}+q_{t+1}\right)\right\}+\mu_{t} \kappa_{t} E_{t}\left\{q_{t+1}\right\}, t=0,1 \\
q_{2}=E_{2}\left\{\beta \frac{U_{c}(3)}{U_{c}(2)}\left(r_{K, 3}+q_{3}\right)\right\}, \\
1=\mu_{2} R^{*}+E_{2}\left\{\beta \frac{U_{c}(3)}{U_{c}(2)} R^{*}\right\}, \\
p_{F}^{*}\left(1+\mu_{t} \vartheta\right) Y_{F, t}=\alpha_{F} Y_{t}, t=0,1,2
\end{gathered}
$$

Variables $\left\{c_{t}, L_{t}, Y_{t}, r_{K, t}\right\}$ are functions of $\left\{q_{t}, Y_{F, t}, \mu_{t}, b_{t+1}^{*}\right\}$, given the initial state $b_{0}^{*}$. The associated capital control can be backed out from the bond Euler equation

$$
\tau_{c, t}=1-\mu_{t} R^{*}-E_{t}\left\{\beta \frac{U_{c}(t+1)}{U_{c}(t)} R^{*}\right\}, t=0,1
$$

\section{B.4 Equilibrium under discretion}

Under discretion, the planner at each period will reset the level of capital control to maximize the lifetime utility of a representative agent conditional on the information up to that period, here the level of borrowing and exogenous shocks. The planner will ignore the impact of current policy on the past households' decisions, while policy makers take such impact into account under commitment.

\section{B.4.1 Social planner's problem at period $\mathrm{t}=1$}

Consider first the policy maker's problem at period $t=1$.

$$
V_{1}\left(b_{1}^{*} ; \kappa_{1}\right)=\max _{\Xi} E_{1}\left\{\sum_{t=1}^{t=3} \beta^{t-1} U\left(c_{t}, l_{t}\right)\right\}
$$

with

$$
\Xi \equiv\left\{q_{t}, Y_{F, t}, \mu_{t}, b_{t+1}^{*}\right\}_{t=1,2}
$$

subject to

$$
\begin{gathered}
\mu_{1}\left[\kappa_{1} E_{1}\left(q_{2}\right)+b_{2}^{*}-\vartheta p_{F}^{*} Y_{F, 1}\right]=0, \\
\kappa_{1} E_{1}\left(q_{2}\right) \geq-b_{2}^{*}+\vartheta p_{F}^{*} Y_{F, 1},
\end{gathered}
$$




$$
\begin{gathered}
\mu_{1} \geq 0, \\
\mu_{2}\left[\kappa_{2} \bar{q}+b_{3}^{*}-\vartheta p_{F}^{*} Y_{F, 2}\right]=0, \\
\kappa_{2} \bar{q} \geq-b_{3}^{*}+\vartheta p_{F}^{*} Y_{F, 2} \\
\mu_{2} \geq 0 \\
q_{1}=E_{1}\left\{\beta \frac{U_{c}(2)}{U_{c}(1)}\left(r_{K, 2}+q_{2}\right)\right\}+\mu_{1} \kappa_{1} E_{1}\left\{q_{2}\right\}, \\
q_{2}=E_{2}\left\{\beta \frac{U_{c}(3)}{U_{c}(2)}\left(r_{K, 3}+q_{3}\right)\right\}, \\
1=\mu_{2} R^{*}+E_{2}\left\{\beta \frac{U_{c}(3)}{U_{c}(2)} R^{*}\right\}, \\
p_{F}^{*}\left(1+\mu_{t} \vartheta\right) Y_{F, t}=\alpha_{F} Y_{t}, t=1,2
\end{gathered}
$$

Variables $\left\{c_{t}, L_{t}, Y_{t}, r_{K, t}\right\}$ are functions of $\left\{q_{t}, Y_{F, t}, \mu_{t}, b_{t+1}^{*}\right\}$, given the initial state $b_{1}^{*}$. The associated capital control can be backed out from the bond Euler equation

$$
\tau_{c, 1}=1-\mu_{1} R^{*}-E_{1}\left\{\beta \frac{U_{c}(2)}{U_{c}(1)} R^{*}\right\}
$$

Once obtain the solution to problem (B.9) given initial condition $\left(b_{1}^{*} ; \kappa_{1}\right)$, we can write the variables of interest and maximal lifetime utility as functions of the beginning-of-period borrowing and exogenous shock, $q_{t}\left(b_{1}^{*} ; \kappa_{1}\right)$, $Y_{F, t}\left(b_{1}^{*} ; \kappa_{1}\right), \mu_{t}\left(b_{1}^{*} ; \kappa_{1}\right), b_{t+1}^{*}\left(b_{1}^{*} ; \kappa_{1}\right), L_{t}\left(b_{1}^{*} ; \kappa_{1}\right), c_{t}\left(b_{1}^{*} ; \kappa_{1}\right), r_{K, t}\left(b_{1}^{*} ; \kappa_{1}\right), \tilde{c}_{t}\left(b_{1}^{*} ; \kappa_{1}\right)$ for $t=1,2$, and $V_{1}\left(b_{1}^{*} ; \kappa_{1}\right)$.

\section{B.4.2 Social planner's problem at period $\mathrm{t}=0$}

At the first period $t=0$, the policy maker faces a following problem

$$
V_{0}\left(b_{0}^{*} ; \kappa_{0}\right)=\max _{\Xi} U\left(c_{0}, l_{0}\right)+\beta E_{0}\left\{V_{1}\left(b_{1}^{*} ; \kappa_{1}\right)\right\}
$$

with

$$
\Xi \equiv\left\{q_{0}, Y_{F, 0}, \mu_{0}, b_{1}^{*}\right\}
$$

subject to

$$
\begin{gathered}
\mu_{0}\left[\kappa_{0} E_{0}\left(q_{1}\left(b_{1}^{*} ; \kappa_{1}\right)\right)+b_{1}^{*}-\vartheta p_{F}^{*} Y_{F, 0}\right]=0, \\
\kappa_{0} E_{0}\left(q_{1}\left(b_{1}^{*} ; \kappa_{1}\right)\right) \geq-b_{1}^{*}+\vartheta p_{F}^{*} Y_{F, 0}, \\
\mu_{0} \geq 0, \\
q_{0}=E_{0}\left\{\beta \frac{U_{c}\left(\tilde{c}_{1}\left(b_{1}^{*} ; \kappa_{1}\right)\right)}{U_{c}\left(\tilde{c}_{0}\right)}\left(r_{K, 1}\left(b_{1}^{*} ; \kappa_{1}\right)+q_{1}\left(b_{1}^{*} ; \kappa_{1}\right)\right)\right\}+\mu_{0} \kappa_{0} E_{0}\left\{q_{1}\left(b_{1}^{*} ; \kappa_{1}\right)\right\}, \\
p_{F}^{*}\left(1+\mu_{0} \vartheta\right) Y_{F, 0}=\alpha_{F} Y_{0} .
\end{gathered}
$$

Once the policymaker at period $t=0$ solves problem (B.10), the allocations across all periods can be pinned down completely. 


\section{B.5 Specification of shocks}

The only exogenous disturbance is the leverage shock $\kappa_{t}$. For simplicity, we assume that uncertainty is resolved in the very beginning of period $t=0$. The leverage parameter is fixed at $\kappa_{t}=0.4$ for $t=0,1,2$. Parameter $\bar{q}$ is chosen such that the credit constraint at period $t=2$ is binding when it also binds at period $t=1$, say $\bar{q}=q_{2}^{F B} / 1.35$, where superscript $F B$ denotes the first-best. This specification makes the 'financial accelerator' work in the first two periods $t=0,1$.

\section{Derivation of import tax}

In the baseline infinite-period model, domestic policy maker has an incentive to manipulate terms of trade and pecuniary externality simultaneously. In order to focus on the role of capital controls for fixing pecuniary externalities, we put an exogenous import tax to correct the terms of trade manipulation in normal times. To simplify the derivation, we assume that the policymaker faces a collateral whose value is exogenously determined. The social planner faces a following problem

$$
\max _{\left\{C_{t}, Y_{t}, L_{t}, e_{t}, b_{t+1}^{*}\right\}} E_{0} \sum_{t=0}^{+\infty} \beta^{t} U\left(C_{t}, L_{t}\right),
$$

subject to

$$
\begin{gathered}
Y_{t}=C_{t}+\left(e_{t}\right)^{\rho} \zeta_{t}^{*}, \\
\left(e_{t}\right)^{\rho} \zeta_{t}^{*}-Y_{F, t} e_{t}=\left(\frac{b_{t+1}^{*}}{R_{t+1}^{*}}-b_{t}^{*}\right) e_{t}, \\
\kappa_{t} \bar{q}+b_{t+1}^{*}-\vartheta Y_{F, t} \geq 0, \\
Y_{t}=A_{t}\left(Y_{F, t}\right)^{\alpha_{F}} L_{t}^{\alpha_{L}} .
\end{gathered}
$$

The optimality conditions can be written as

$$
\begin{gathered}
w_{t}=\chi L_{t}^{\nu}, \\
\frac{\rho}{\rho-1} e_{t}\left(1+\mu_{t} \vartheta\right) Y_{F, t}=\alpha_{F} Y_{t}, \\
1=\mu_{t} R_{t+1}^{*}+E_{t}\left\{\beta \frac{U_{c}(t+1)}{U_{c}(t)} \frac{e_{t+1}}{e_{t}} R_{t+1}^{*}\right\} .
\end{gathered}
$$

There is a constant export markup $\rho /(\rho-1)$ in the social planner's optimality conditions. To be consistent with this allocation and also following the literature, we impose a constant import tax $\tau_{N, t} \equiv 1 /(\rho-1)$ in the competitive equilibrium. With this constant tax, capital controls do not target the terms of trade manipulation in normal times.

\section{Optimal capital controls under commitment}

This section derives the optimality conditions faced by a Ramsey planner under commitment. For simplicity, we consider a perfect foresight model, but the arguments in the perfect foresight model go through unchanged for the stochastic infinite horizon model.

Assume that the exogenous shocks are realized at the very beginning of the initial period $t=0$. The planner chooses a sequence of state-contingent capital inflow $\operatorname{tax}\left\{\tau_{c, t}\right\}_{t=0}^{+\infty}$ at period $t=0$ to maximize a representative household's lifetime utility and commits to honor this policy profile at every following period. Equivalently, the 
planner chooses a sequence of allocations and prices subjective to the implementability constraints. The inflow $\operatorname{tax} \tau_{c, t}$ is then backed out from the household's bond Euler equation. We consider first a model without nominal rigidities.

The problem faced by the Ramsey planner reads

$$
\max _{\{\Xi\}} \sum_{t=0}^{+\infty} \beta^{t} U\left(\tilde{C}_{t}\right), \text { with } \tilde{C}_{t} \equiv C_{t}-\chi \frac{L_{t}^{1+\nu}}{1+\nu}
$$

with

$$
\Xi=\left\{\tilde{C}_{t}, L_{t}, Y_{t}, Y_{F, t}, b_{t+1}^{*}, q_{t}, \eta_{t}, r_{K, t}, e_{t}\right\}
$$

subject to

$$
\begin{gathered}
\lambda_{2, t}:-q_{t}+\mu_{t} \kappa_{t} e_{t} \frac{q_{t+1}}{e_{t+1}}+\beta \frac{U_{c}(t+1)}{U_{c}(t)}\left(r_{K, t+1}+q_{t+1}\right)=0 \\
\lambda_{6, t}:\left(1+\tau_{N, t}\right) e_{t}\left(1+\mu_{t} \vartheta\right) Y_{F, t}-\alpha_{F} Y_{t}=0 \\
\lambda_{7, t}: \chi L_{t}^{1+\nu}-\alpha_{L} Y_{t}=0 \\
\lambda_{8, t}: r_{K, t}-\alpha_{K} Y_{t}=0 \\
\lambda_{9, t}: \kappa_{t} \frac{q_{t+1}}{e_{t+1}}+b_{t+1}^{*}-\vartheta Y_{F, t}\left(1+\tau_{N, t}\right)-a l m_{t}=0 \\
\lambda_{10, t}:-Y_{t}+A_{t}\left(Y_{F, t}\right)^{\alpha} L_{t}^{\alpha}=0 \\
\lambda_{12, t}: Y_{t}-\tilde{C}_{t}-\chi \frac{L_{t}^{1+\nu}}{1+\nu}-e_{t}^{\rho} \zeta_{t}^{*}=0 \\
\lambda_{13, t}:\left(e_{t}\right)^{\rho-1} \zeta_{t}^{*}-Y_{F, t}-\left(\frac{b_{t+1}^{*}}{R_{t+1}^{*}}-b_{t}^{*}\right)=0 .
\end{gathered}
$$

where $\lambda_{j, t}$ with $j=2,6,7,8,9,10,12,13$ denote the Lagrange multipliers for the corresponding constraints. $\mu_{t}=$ $\left(\max \left(0, \eta_{t}\right)\right)^{3}$ and alm $_{t}=\left(\max \left(0,-\eta_{t}\right)\right)^{3}$. The optimality conditions are written as follows.

The effective consumption $\tilde{C}_{t}$ at period $t=0$

$$
U_{c}(0)-\lambda_{12,0}-\lambda_{2,0} \beta \frac{U_{0}(1)}{U_{c}^{2}(0)} U_{c c}(0)\left(r_{K, 1}+q_{1}\right)
$$

and at period $t>0$

$$
U_{c}(t)-\lambda_{12, t}-\lambda_{2, t} \beta \frac{U_{t}(t+1)}{U_{c}^{2}(t)} U_{c c}(t)\left(r_{K, t+1}+q_{t+1}\right)+\lambda_{2, t-1} \frac{U_{c c}(t)}{U_{c}(t-1)}\left(r_{K, t}+q_{t}\right)=0
$$

Labor $L_{t}$

$$
\lambda_{7, t} \chi(1+\nu) L_{t}^{\nu}+\lambda_{10, t} \alpha_{L} \frac{Y_{t}}{L_{t}}-\lambda_{12, t} \chi L_{t}^{\nu}=0
$$

Total production $Y_{t}$

$$
-\lambda_{6, t} \alpha_{F}-\lambda_{7, t} \alpha_{L}-\lambda_{8, t} \alpha_{K}-\lambda_{10, t}+\lambda_{12, t}=0
$$

Imported goods $Y_{F, t}$

$$
\lambda_{6, t}\left(1+\tau_{N, t}\right) e_{t}\left(1+\vartheta \mu_{t}\right)-\lambda_{9, t} \vartheta\left(1+\tau_{N, t}\right)+\lambda_{10, t} \frac{\alpha_{F} Y_{t}}{Y_{F, t}}-\lambda_{13, t}=0
$$


Capital price $q_{t}$ at period $t=0$

$$
\lambda_{2,0}=0,
$$

and at period $t>0$

$$
-\lambda_{2, t}+\frac{\lambda_{2, t-1}}{\beta} \mu_{t-1} \kappa_{t-1} e_{t-1} \frac{1}{e_{t}}+\frac{\lambda_{9, t-1}}{\beta} \kappa_{t-1} \frac{1}{e_{t}}+\lambda_{2, t-1} \frac{U_{c}(t)}{U_{c}(t-1)}=0,
$$

Lagrange multiplier for collateral constraint $\eta_{t}$

$$
\lambda_{2, t} \kappa_{t} e_{t} \frac{q_{t+1}}{e_{t+1}} \frac{d \mu_{t}}{d \eta_{t}}+\lambda_{6, t}\left(1+\tau_{N, t}\right) e_{t} Y_{F, t} \vartheta \frac{d \mu_{t}}{d \eta_{t}}-\lambda_{9, t} \frac{d a l m_{t}}{d \eta_{t}}=0
$$

Marginal product of capital $r_{K, t}$ at period $t=0$

$$
\lambda_{8,0}=0
$$

and at period $t>0$

$$
\lambda_{8, t}+\lambda_{2, t-1} \frac{U_{c}(t)}{U_{c}(t-1)}=0
$$

Real exchange rate $e_{t}$ at period $t=0$

$$
\lambda_{2,0} \mu_{0} \kappa_{0} \frac{q_{1}}{e_{1}}+\lambda_{6,0}\left(1+\tau_{N, t}\right) Y_{F, 0}\left(1+\mu_{0} \vartheta\right)-\lambda_{12,0} \rho e_{0}^{\rho-1} \zeta_{0}^{*}+\lambda_{13,0}(\rho-1) e_{0}^{\rho-2} \zeta_{0}^{*}=0,
$$

and at period $t>0$,

$$
\begin{gathered}
\lambda_{2, t} \mu_{t} \kappa_{t} \frac{q_{t+1}}{e_{t+1}}+\lambda_{6, t}\left(1+\tau_{N, t}\right) Y_{F, t}\left(1+\mu_{t} \vartheta\right)-\lambda_{12, t} \rho e_{t}^{\rho-1} \zeta_{t}^{*}+\lambda_{13, t}(\rho-1) e_{t}^{\rho-2} \zeta_{t}^{*} \\
-\frac{\lambda_{2, t-1}}{\beta} \mu_{t-1} \kappa_{t-1} e_{t-1} \frac{q_{t}}{e_{t}^{2}}-\frac{\lambda_{9, t-1}}{\beta} \kappa_{t-1} \frac{q_{t}}{e_{t}^{2}}=0,
\end{gathered}
$$

Borrowing $b_{t+1}^{*}$

$$
\begin{gathered}
\lambda_{2, t} \mu_{t} \kappa_{t} e_{t} \frac{\partial\left(q_{t+1} / e_{t+1}\right)}{\partial b_{t+1}^{*}}+\frac{\lambda_{2, t} \beta}{U_{c}(t)} \frac{\partial\left(U_{c}(t+1)\left(r_{K, t+1}+q_{t+1}\right)\right)}{\partial b_{t+1}^{*}} \\
+\lambda_{9, t}-\frac{\lambda_{13, t}}{R_{t+1}^{*}}+\beta \lambda_{13, t+1}++\lambda_{9, t} \kappa_{t} \frac{\partial\left(q_{t+1} / e_{t+1}\right)}{\partial b_{t+1}^{*}}=0
\end{gathered}
$$

Under commitment, the Ramsey planner takes into account of the effects of future allocations and prices on the past allocations and prices, which works through Lagrange multipliers $\lambda_{2, t-1}$ and $\lambda_{9, t-1}$. The logic in this model is the same as that in the simplified finite-period model.

Now consider a model with nominal rigidities. Policy instruments are monetary policy and capital controls. Note that nominal rigidities are introduced through price adjustment costs deviating from a constant inflation target. Any deviation from the target in normal times (non-crisis episodes) will reduce total output available to private agents and distort factor prices in the economy. If monetary policy were in place, the monetary authority would completely neutralize nominal rigidities through strict price stability period by period. This optimal monetary policy holds both under discretion and under commitment in normal times. With both monetary policy and capital control instruments at hand, monetary policy can completely stabilize domestic prices to offset nominal rigidities both in normal times and in crisis, and the optimal capital controls are laid down as above. 


\section{D.1 Optimal capital controls under discretion}

Under discretion, a Ramsey planner has a chance to re-optimize her problem at every period and does not take into account of the effects of current policy on the responses of past endogenous variables. Therefore, the only endogenous state variable inherited from the previous planner is borrowing $b_{t+1}^{*}$. The optimality conditions under discretion are the same conditions as those in period $t=0$ (equation D.9-D.17), $\lambda_{2, t-1}=\lambda_{9, t-1}=0$, implying $\lambda_{2, t}=\lambda_{8, t}=0$, and $\lambda_{12, t}=U_{c}(t)$.

First notice that when the collateral constraint binds at period $t \mu_{t}>0$, equation (D.14) implies that $\lambda_{6, t}=0$. From equation (D.16), $\lambda_{13, t}=\lambda_{12, t} e_{t} \rho /(\rho-1)$. Combining equation (D.11) and (D.10) yields $\lambda_{7, t}=0$ and $\lambda_{10, t}=$ $\lambda_{12, t}$. The bond Euler equation (D.17) can then be written as

$$
1=\beta \frac{U_{c}(t+1)}{U_{c}(t)} \frac{e_{t+1}}{e_{t}} R_{t+1}^{*}+\frac{\lambda_{9, t}}{\lambda_{13, t}} R_{t+1}^{*}+\frac{\lambda_{9, t}}{\lambda_{13, t}} R_{t+1}^{*} \kappa_{t} \frac{\partial\left(q_{t+1} / e_{t+1}\right)}{\partial b_{t+1}^{*}}
$$

When the import tax is given by $\tau_{N, t}=1 /(\rho-1)$, equation (D.12) can be simplified as

$$
\lambda_{9, t}=\lambda_{10, t} e_{t} \mu_{t}>0
$$

and accordingly equation (D.18) can be rewritten as

$$
1=\beta \frac{U_{c}(t+1)}{U_{c}(t)} \frac{e_{t+1}}{e_{t}} R_{t+1}^{*}+\frac{\rho-1}{\rho} \mu_{t} R_{t+1}^{*}+\frac{\rho-1}{\rho} \mu_{t} R_{t+1}^{*} \kappa_{t} \frac{\partial\left(q_{t+1} / e_{t+1}\right)}{\partial b_{t+1}^{*}}
$$

Alternatively,

$$
1=\beta \frac{U_{c}(t+1)}{U_{c}(t)} \frac{e_{t+1}}{e_{t}} R_{t+1}^{*}+\mu_{t} R_{t+1}^{*}+\tau_{c, t}
$$

with

$$
\begin{aligned}
\tau_{c, t} & \equiv-\frac{1}{\rho} \mu_{t} R_{t+1}^{*}+\frac{\rho-1}{\rho} \mu_{t} R_{t+1}^{*} \kappa_{t} \frac{\partial\left(q_{t+1} / e_{t+1}\right)}{\partial b_{t+1}^{*}} \\
& =\frac{\mu_{t} R_{t+1}^{*}}{\rho}\left[-1+(\rho-1) \kappa_{t} \frac{\partial\left(q_{t+1} / e_{t+1}\right)}{\partial b_{t+1}^{*}}\right]
\end{aligned}
$$

When the elasticity $\rho$ is large and the value of collateralized assets $q_{t+1} / e_{t+1}$ is steep with respect to borrowing $b_{t+1}^{*}$, the Ramsey planner under discretion always taxes capital inflow $\tau_{c, t}>0$ whenever the collateral constraint binds. Similarly, when the collateral constraint does not bind at period $t$, one can show that $\lambda_{6, t}=0, \lambda_{7, t}=0, \lambda_{9, t}=0$, $\lambda_{10, t}=\lambda_{12, t}$ and $\lambda_{13, t}=\lambda_{12, t} e_{t} \rho /(\rho-1)$.

\section{E Proof of Proposition 2}

We state the proof explicitly for a deterministic finite horizon case based on the optimality conditions derived from Appendix D, but the results go through unchanged for the stochastic infinite horizon model.

Consider first the Ramsey planner decisions in periods $t=\{0,1,2,3, \ldots\}$ in a perfect foresight model where constraints do not bind in $t=\{0,1\}$ and bind with certainty in $t=\{2,3\}$. Note that the Lagrange multipliers for the capital Euler equation $\lambda_{2, t}$ and the collateral constraint $\lambda_{9, t}$ carry the constraints under commitment into period $t+1$. In the optimality conditions under commitment, only $\left(\lambda_{2, t-1}, \lambda_{9, t-1}\right)$ and $\left(\lambda_{2, t}, \lambda_{9, t}\right)$ appear, and not the multipliers $\left(\lambda_{2, t+1}, \lambda_{9, t+1}\right)$. Therefore, capital controls are not 'macro-prudential' in our model economy.

When $\mu_{0}=0$ in period $t=0$, we have $\lambda_{2,0}=\lambda_{9,0}=0$ whenever $\lambda_{2,-1}=\lambda_{9,-1}=0$. In period $t=1$, we still have $\lambda_{2,1}=\lambda_{9,1}=0$ if $\mu_{1}=0$ both under commitment and under discretion, although constraints will bind at $t=2$ with 
certainty. We then have $\tau_{c, 0}=\tau_{c, 1}=0$.

Second, consider a more general case. In the case without commitment, $\lambda_{2, t}=\lambda_{9, t}=0$ as long as $\mu_{t}=0$ for any period $t$ as shown in Appendix D.1, even though the collateral constraint binds next period, and thereby $\tau_{c, t}=0$. In the case with commitment, when the collateral constraints don't bind for many periods to the extent that $\lambda_{2, t-1}=\lambda_{9, t-1}=0$, the argument starting from period $t=0$ above still goes through and $\tau_{c, t}=0$ if $\mu_{t}=0$. Note that the crisis is rare and isn't persistent, the statement that $\tau_{c, t}=0$ when $\mu_{t}=0$ holds most of time under commitment.

The argument goes through unchanged if the constraint binds only with some probability in the next period.

\section{F A model with sticky prices and sticky wages}

We detail here only the model equations that change, rather than present the entire model again. We interpret households now as being endowed with a specific type of labor, $l_{t}(j)$, for which they are the monopoly supplier to the market. These labor services are aggregated into a labor composite

$$
L_{t}=\left(\int_{0}^{1} l_{t}(j)^{\frac{\theta_{W}-1}{\theta_{W}}} d j\right)^{\frac{\theta_{W}}{\theta_{W}-1}},
$$

where $\theta_{W}>1$ is the elasticity of substitution between different types of labor. The wage rate for one unit of aggregate labor services is

$$
W_{t}=\left(\int_{0}^{1} W_{t}(j)^{1-\theta_{W}} d j\right)^{\frac{1}{1-\theta_{W}}}
$$

and the demand for labor of type $j$ is

$$
l_{t}(j)=\left(\frac{W_{t}(j)}{W_{t}}\right)^{-\theta_{W}} L_{t}
$$

For simplicity, we permit trade in a full set of contingent securities to eliminate differences across types.

Labor income for a household with type $j$ labor now has a new term. In the budget constraint labor income is reduced by a fraction $\psi_{t}(j)$, which will reflect resources lost in the adjustment of individual nominal wages. Following Varian (1975) and Kim and Ruge-Murcia (2009), we permit asymmetric adjustment:

$$
\psi_{t}\left(\Omega_{t}^{i n d}\right)=\frac{\phi_{W}}{\gamma_{W}^{2}}\left[\exp \left(\gamma_{W}\left(\Omega_{t}^{i n t}-1\right)\right)-\gamma_{W}\left(\Omega_{t}^{i n t}-1\right)-1\right]
$$

where

$$
\Omega_{t}^{i n d}=\frac{W_{t}}{\pi_{t}^{\varphi} W_{t-1}}
$$

$\varphi$ captures indexation of nominal wages to inflation, $\phi_{W}$ captures the convexity of adjustment costs, and $\gamma_{W}$ controls the asymmetry (specifically, $\gamma_{W}<0$ implies it is costlier to reduce than increase nominal wages).

We consider only symmetric equilibrium where nominal wages do not depend on $j$, leading to the wage Phillips curve

$$
\begin{aligned}
0= & \theta_{W}\left(\frac{\chi l_{t}^{\nu}}{w_{t}}\right)-\left(\theta_{W}-1\right)\left(1+\tau_{W}-\psi_{t}\left(\Omega_{t}^{i n d}\right)\right)-\frac{\pi_{W, t}}{\pi_{t}^{\varphi}} \frac{\phi_{W}}{\gamma_{W}}\left[\exp \left(\gamma_{W}\left(\Omega_{t}^{i n d}-1\right)\right)-1\right]+ \\
& \beta E_{t}\left[\frac{U_{c}(t+1)}{U_{c}(t)} \frac{\pi_{W, t+1}^{2}}{\pi_{t+1}^{1+\varphi}} \frac{l_{t+1}}{l_{t}} \frac{\phi_{W}}{\gamma_{W}}\left[\exp \left(\gamma_{W}\left(\Omega_{t+1}^{i n d}-1\right)\right)-1\right]\right]
\end{aligned}
$$

with wage inflation $\pi_{W, t}=\frac{W_{t}}{W_{t-1}}$. 
If wages are costlessly to adjust $\left(\phi_{W}=0\right)$ then the real wage equals the disutility of labor times a constant markup,

$$
w_{t}=\frac{\theta_{W}}{\theta_{W}-1} \frac{1}{1+\tau_{W}} \chi l_{t}^{\nu}
$$

we set $\tau_{W}=1 /\left(\theta_{W}-1\right)$ to eliminate the monopoly distortion under flexible wages. In general, the evolution of the real wage is determined the gap between wage inflation and price inflation,

$$
w_{t}=\frac{\pi_{W, t}}{\pi t} w_{t-1}
$$

We also need to modify the market clearing condition for composite consumption goods to account for the resources lost via wage adjustment

$$
Y_{t}-\phi\left(\pi_{t}\right) Y_{t}-w_{t} L_{t} \psi_{t}\left(\Omega_{t}^{i n t}\right)=C_{t}+X_{t}+q_{t}\left(K_{t+1}-K_{t}\right)
$$

There are three more parameters to be calibrated, $\phi_{W}, \theta_{W}$ and $\gamma_{W}$, in the this extension. We set $\phi_{W}=32$, $\theta_{W}=3.5$ as in Kim and Ruge-Murcia (2009), and focus on a small downward wage asymmetry $\gamma_{W}=-20$ for the illustrative purpose. The wage indexation parameter is set as $\varphi=0$ to study the nominal wage rigidity.

\section{G The solution algorithms}

\section{G.1 The solution algorithm for the competitive equilibrium}

We solve for policy functions in the competitive equilibrium based on the first-order necessary conditions in Appendix A. First, the following transformation is used to take care of the occasionally binding constraints:

$$
\begin{gathered}
\mu_{t}=\left(\max \left(0, \eta_{t}\right)\right)^{3} \\
\kappa_{t} E_{t}\left(\frac{q_{t+1}}{e_{t+1}}\right)+b_{t+1}^{*}-\left(1+\tau_{N, t}\right) \vartheta Y_{F, t}=\operatorname{alm} m_{t} \equiv\left(\max \left(0,-\eta_{t}\right)\right)^{3}
\end{gathered}
$$

where $\eta_{t}$ is a real number.

Second, the endogenous state variable $b_{t}^{*}$ is discretized into 300 grid points. Combining with 8 grid points for the three exogenous shocks $Z_{t} \equiv\left(A_{t}, R_{t+1}^{*}, \kappa_{t}\right)$, there are $300 \times 8$ grid points in total. Third, we make use of time iteration to find a fixed point of the model.

Note that the following five variables, representing inputs, total output, the return on capital, and consumption can be solved analytically as functions of bond holdings and the real exchange rate

$$
\begin{gathered}
Y_{F, t}=\left(e_{t}\right)^{\rho-1} \zeta_{t}^{*}-\left(\frac{b_{t+1}^{*}}{R_{t+1}^{*}}-b_{t}^{*}\right) \\
L_{t}=\left[\frac{p_{M, t} \alpha_{L} A_{t}\left(Y_{F, t}\right)^{\alpha_{F}}}{\chi}\right]^{\frac{1}{1+\nu-\alpha_{L}}}, \\
Y_{t}=A_{t}\left(Y_{F, t}\right)^{\alpha_{F}} L_{t}^{\alpha_{L}} \\
r_{K, t}=\alpha_{K} p_{M, t} Y_{t}, \\
\tilde{C}_{t}=Y_{t}\left[1-\phi\left(\pi_{t}\right)\right]-\chi \frac{L_{t}^{1+\nu}}{1+\nu}-e_{t}^{\rho} \zeta_{t}^{*} .
\end{gathered}
$$


Given policy functions for future variables $b_{t+2}^{*}\left(b_{t+1}^{*}, Z_{t+1}\right), q_{t+1}\left(b_{t+1}^{*}, Z_{t+1}\right), e_{t+1}\left(b_{t+1}^{*}, Z_{t+1}\right), \eta_{t+1}\left(b_{t+1}^{*}, Z_{t+1}\right)$, $p_{M, t+1}\left(b_{t+1}^{*}, Z_{t+1}\right)$, and $\pi_{t+1}\left(b_{t+1}^{*}, Z_{t+1}\right)$, we can solve for $b_{t+1}^{*}, L_{t}, \tilde{C}_{t}, Y_{t}, Y_{F, t}, q_{t}, \eta_{t}, r_{K, t}, e_{t}, p_{M, t}$ and $\pi_{t}$ at each grid point $\left(b_{t}^{*}, Z_{t}\right)$ from the system of equilibrium conditions by using a Newton-type nonlinear solver. Whenever the nonlinear solver fails to find a solution, we then apply a homotopy path-following algorithm to find a good initial guess for the nonlinear solver (Eaves and Schmedders, 1999). When policy functions in two consecutive periods are close enough, say, the maximal difference is below $\epsilon=10^{-5}$, the iteration stops; otherwise redo the iteration starting from new policy functions obtained at period $t$.

\section{G.2 The solution algorithm for the Ramsey problems}

We solve the Ramsey planner's problem based on value function $V\left(b_{t}^{*}, Z_{t}\right)$ directly, subject to the implementability constraints, which are defined in the main text. Similarly to the competitive equilibrium, the occasionally binding constraint and its Lagrange multiplier are replaced by two smooth functions (G.1-G.2). We use time iteration to find a fixed point of the model.

Given policy functions for future variables $b_{t+2}^{*}\left(b_{t+1}^{*}, Z_{t+1}\right), q_{t+1}\left(b_{t+1}^{*}, Z_{t+1}\right), e_{t+1}\left(b_{t+1}^{*}, Z_{t+1}\right), \eta_{t+1}\left(b_{t+1}^{*}, Z_{t+1}\right)$, $p_{M, t+1}\left(b_{t+1}^{*}, Z_{t+1}\right), \pi_{t+1}\left(b_{t+1}^{*}, Z_{t+1}\right)$, and value function $V_{t+1}\left(b_{t+1}^{*}, Z_{t+1}\right)$, we can find $b_{t+1}^{*}, L_{t}, \tilde{C}_{t}, Y_{t}, Y_{F, t}, q_{t}, \eta_{t}$, $r_{K, t}, e_{t}, p_{M, t}$ and $\pi_{t}$ to maximize the current value function $V_{t}\left(b_{t}^{*}, Z_{t}\right)$, subject to the implementability constraints, at each grid point $\left(b_{t}^{*}, Z_{t}\right)$, by using a feasible sequential quadratic programming (Schittkowski, 2014). When policy functions and value function in two consecutive periods are close enough, say, the maximal difference is below $\epsilon=10^{-5}$, the iteration stops; otherwise redo the iteration starting from new policy functions obtained at period $t$. 